\title{
Article \\ A Tale of Two Transcriptomic Responses in Agricultural Pests via Host Defenses and Viral Replication
}

\author{
Pramod Pantha $\mathbb{(}$, Subbaiah Chalivendra $(\mathbb{D}$, Dong-Ha Oh $\mathbb{(}$, Bret D. Elderd * and Maheshi Dassanayake *(i) \\ Department of Biological Sciences, Louisiana State University, Baton Rouge, LA 70803, USA; \\ ppanth1@lsu.edu (P.P.); subbaiahchalivendra@gmail.com (S.C.); ohdongha@lsu.edu (D.-H.O.) \\ * Correspondence: elderd@lsu.edu (B.D.E.); maheshid@lsu.edu (M.D.)
}

Citation: Pantha, P.; Chalivendra, S.; Oh, D.-H.; Elderd, B.D.; Dassanayake, M. A Tale of Two Transcriptomic Responses in Agricultural Pests via Host Defenses and Viral Replication. Int. J. Mol. Sci. 2021, 22, 3568. https://doi.org/10.3390/ ijms22073568

Academic Editor: Hans Eggenkamp

Received: 8 March 2021

Accepted: 26 March 2021

Published: 30 March 2021

Publisher's Note: MDPI stays neutral with regard to jurisdictional claims in published maps and institutional affiliations.

Copyright: (c) 2021 by the authors. Licensee MDPI, Basel, Switzerland. This article is an open access article distributed under the terms and conditions of the Creative Commons Attribution (CC BY) license (https:// creativecommons.org/licenses/by/ $4.0 /)$.

\begin{abstract}
Autographa californica Multiple Nucleopolyhedrovirus (AcMNPV) is a baculovirus that causes systemic infections in many arthropod pests. The specific molecular processes underlying the biocidal activity of AcMNPV on its insect hosts are largely unknown. We describe the transcriptional responses in two major pests, Spodoptera frugiperda (fall armyworm) and Trichoplusia ni (cabbage looper), to determine the host-pathogen responses during systemic infection, concurrently with the viral response to the host. We assembled species-specific transcriptomes of the hemolymph to identify host transcriptional responses during systemic infection and assessed the viral transcript abundance in infected hemolymph from both species. We found transcriptional suppression of chitin metabolism and tracheal development in infected hosts. Synergistic transcriptional support was observed to suggest suppression of immune responses and induction of oxidative stress indicating disease progression in the host. The entire AcMNPV core genome was expressed in the infected host hemolymph with a proportional high abundance detected for viral transcripts associated with replication, structure, and movement. Interestingly, several of the host genes that were targeted by AcMNPV as revealed by our study are also targets of chemical insecticides currently used commercially to control arthropod pests. Our results reveal an extensive overlap between biological processes represented by transcriptional responses in both hosts, as well as convergence on highly abundant viral genes expressed in the two hosts, providing an overview of the host-pathogen transcriptomic landscape during systemic infection.
\end{abstract}

Keywords: baculovirus; hemolymph; chitin metabolism; extracellular matrix organization; cuticle development; biopesticides

\section{Introduction}

Baculoviruses are highly virulent arthropod-specific viruses [1]. They usually have specific host ranges and most of them only infect congeneric insect species. Autographa californica Multicapsid Nucleopolyhedrovirus (AcMNPV) is the most notable exception in the Baculoviridae family of viruses, which infects over 35 species belonging to 11 lepidopteran families [2].

Baculoviruses have large rod-shaped nucleocapsids with circular DNA genomes. The sequenced AcMNPV genomes are $\sim 134 \mathrm{kbp}$ in size and contain 150 tightly spaced genes $[3,4]$. AcMNPV is widely used as a molecular tool in gene therapy; a vector in engineered protein production using insect cell cultures; and a potent biopesticide in integrated pest management systems that could spare beneficial insects, especially in ecologically sensitive areas [5].

AcMNPV is found as two distinct virion phenotypes [6]. First, the occlusion-derived virus is transmitted among insects primarily via horizontal transmission when uninfected hosts inadvertently consume the virus. If enough virus is consumed, a fatal infection occurs. The virus replicates within the larva until the virus triggers the liquefaction of the insect host, which releases occlusion-derived viruses onto nearby foliage [7]. After the virus is released to the environment, uninfected larvae eat the newly contaminated 
foliage and the cycle continues [8]. Second, within the insect host following infection of the midgut epithelial cells, the budded form of the virus causes secondary infection in the open circulatory system and, subsequently, invades cells in other tissue types [9]. Once an individual larva is infected, the larva does not continue to grow or molt to larger instars, whereas uninfected individuals do. Besides horizontal transmission, vertical transmission between mother and offspring may also occur. However, vertical transmission often results in a "covert" infection that does not kill the host [8].

The fall armyworm (Spodoptera frugiperda) and the cabbage looper (Trichoplusia ni) are among major agricultural pests vulnerable to AcMNPV infection. These two pests together pose a significant threat to global food security, affecting over 150 crops including corn, rice, soybean, and cotton. The total yield loss by $S$. frugiperda alone in 12 maize producing African countries in 2017 was estimated to be between US\$2.48 and $\$ 6.19$ billion [10]. If appropriate control measures are not applied, these pests together can exacerbate the problem of food security and livelihood of many small farmers worldwide due to their wide host range. They are difficult to control due to their rapid spread and the development of their resistance to many insecticides [11,12]. Therefore, AcMNPV strains that can naturally infect these serious agricultural pests offer a promising mode of pest control. However, it is imperative to understand the mode of infection, disease progression, and epidemiology of a naturally occurring virus before its commercialization, to minimize unintentional secondary effects [12].

Both host species are widespread multivoltine (i.e., multiple generations per year) pests from the same family Noctuidae [13-15]. After hatching, S. frugiperda has six larval instars or development stages before the larvae pupate and later emerge as adults, whereas T. $n i$ has five larval instars $[16,17]$. These two pests are readily infected in nature by baculoviruses, particularly when they reach large population densities [1].

In vivo studies investigating the genetic basis for AcMNPV infection and the integrated host responses are quite limited. Due to difficulties in generating the synchronized samples post infection, there are very few studies on the systemic infection phase of AcMNPV on host and viral transcription. Most studies exploring transcriptional regulation of these host-pathogen interactions use cell cultures infected with the virus. The transcriptome responses of S. frugiperda $[18,19]$ and T. ni $[20,21]$ cell cultures infected with AcMNPV have shown quite divergent transcriptional profiles, which makes it difficult to deduce the impact of these responses in intact organisms. Recently, Shrestha et al. described the in vivo transcriptional response of T. ni during AcMNPV infection [22]. They reported the oral to midgut tissue-specific transcriptomic responses at the primary stage of infection in 5 th instar larvae. In vivo studies that explore the transcriptional dynamics in response to AcMNPV infections appear to be even fewer in S. frugiperda. To our knowledge, studies exploring gene expression profiles of systemic AcMNPV infections in intact hosts along with reciprocal viral transcriptomes are absent either in S. frugiperda or T. ni.

In this study, we provide reference transcriptomes for the hemolymph in 4th instar larvae and report the host-pathogen transcriptional responses associated with the systemic infection phase as represented in the hemolymph in S. frugiperda and T. ni during AcMNPV infection. The transcriptional profiles in the host hemolymph captured in our data link host responses to the virus as well as the reciprocal viral responses to the hosts. Our results indicate major transcriptional changes to support initiation of critical cellular and developmental adjustments in the hosts during pathogenesis.

\section{Results}

\subsection{Lethal Effects of AcMNPV on S. frugiperda and T. ni}

Clearly, both $S$. frugiperda and T. ni were adversely affected by increased doses of AcMNPV (Figure 1a,b), resulting in the death of a large proportion of larvae at higher doses. Despite these two insects being from the noctuidae family, S. frugiperda required a much larger dose of the virus to become infected as compared to T. ni (Figure 1a,b). Additionally, S. frugiperda has an LD50 (lethal dose at which 50\% of the larvae would be 
expected to succumb to viral infection) of 3.4 and T. $n i$ has an LD50 of 2.0, which is similar in magnitude difference to the LD95 (lethal dose at which 95\% of the larvae would be expected to succumb to viral infection). Given the relatively good fit of the logistic model to the data and the relatively narrow credible intervals, the median LD95 for both species was reasonably well estimated. For the subsequent transcriptome analysis, we infected $S$. frugiperd $a$ and T. ni using the estimated species-specific LD95, $10^{4.5}$ and $10^{3}$ occlusion bodies, respectively, using the same diet cube method as used in the dose-response experiment (see the Materials and Methods section). Note that there is over a 10-fold difference in the LD95 between the species (Figure 1c).

(a)

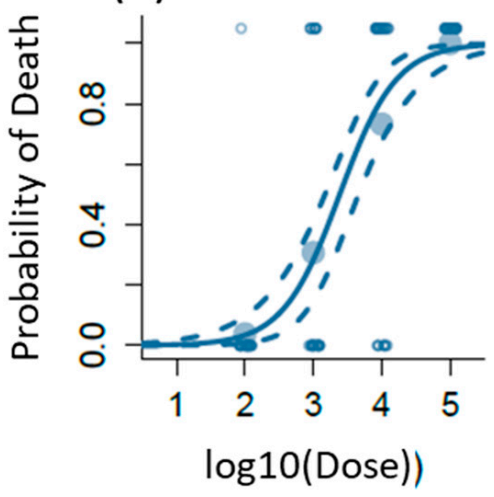

(b)

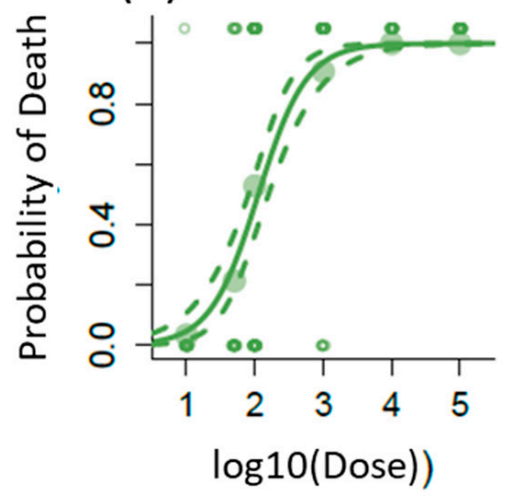

(c)

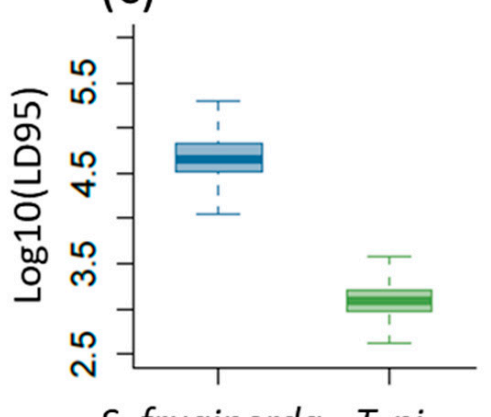

S. frugiperda T. ni

Figure 1. Lethal AcMNPV dose determination for Spodoptera frugiperda and Trichoplusia ni. The effects of increasing doses of baculoviruses on the probability of larval death for (a) S. frugiperda and (b) T. ni along with the corresponding (c) box plot of the lethal dose at which $95 \%$ of the individuals would be expected to die identified as LD95. For (a) and (b), the solid line is the median dose-response curve and the dashed lines are the $95 \%$ credible intervals for the curve. The large filled points represent the mean response for each dose and the small open points are the individual data. These data are jittered for ease of presentation. For [c] the dark line of the box plot is the median with the box encompassing the interquartile range between the first and third quartiles and the whiskers represent 1.5 times the interquartile range.

\subsection{De Novo Assembly and Annotation of S. frugiperda and T. ni 4th Instar Reference Transcriptomes}

We report the most curated reference transcriptomes that represent the hemolymph tissue of $S$. frugiperda and T. ni currently available. On average, 62 million raw reads were obtained for each RNA-seq sample generated for S. frugiperda and T. ni (Supplementary Table S1). The fully assembled transcriptomes are available at NCBI BioProject PRJNA664633. We selected 17,908 S. frugiperda transcripts (mean length $1458 \mathrm{nt}$ ) and 19,472 T. ni transcripts (mean length $1773 \mathrm{nt}$ ) to represent the protein-coding reference transcriptomes (Table 1). The number and length distribution of total protein-coding transcript models in the current reference transcriptomes (Supplementary Figure S1a,b) were comparable to the protein-coding transcripts available for Bombyx mori [23], Helicoverpa armigera [24], Spodoptera litura [25], and the genome of T. ni [26] (Supplementary Figure $\mathrm{S} 1 \mathrm{c}, \mathrm{d})$. Our predicted protein coding transcripts mainly contained complete open reading frames (ORFs) with start and end codons included in the transcript model (Supplementary Figure S2a). We were able to map $>75 \%$ of the initial RNA-seq reads to the reference transcriptomes for both species (Supplementary Table S2).

As $D$. melanogaster genes provided the highest number of functional attributes available for an arthropod model, we first annotated 5878 S. frugiperda and 6219 T. ni transcript models based on the $D$. melanogaster reference models when possible (see methods). The NCBI insect-Refseq database was used to annotate another 9273 transcripts from $S$. frugiperda and 9751 transcripts from T. ni (Supplementary Figure S3a). The remaining transcripts were subjected to BLASTX [27] against the NCBI-nr databases to annotate 1278 S. frugiperda and 888 T. ni transcripts. A final pool of remaining transcripts that did not 
show convincing similarity to other known eukaryotic transcripts (1479 S. frugiperda and 2614 T. ni transcripts) were annotated as "unknown putative proteins." The annotation of reference transcriptome for both species is provided in the Supplementary Table S3.

Table 1. Summary of de novo assembled reference transcriptomes of S. frugiperda and T. ni.

\begin{tabular}{|c|c|c|}
\hline \multirow{2}{*}{ Transcriptome Assembly Features } & S. frugiperda & T. $n i$ \\
\hline & Coding $^{a}$ (Non-Coding ${ }^{b}$ ) & Coding $^{a}$ (Non-Coding $\left.{ }^{b}\right)$ \\
\hline Total assembled transcripts & $17,908(101,169)$ & $19,472(147,934)$ \\
\hline Percent GC & $42.68(35.28)$ & $41.16(35.24)$ \\
\hline Contig N50 (nt) & $2279(532)$ & $2955(656)$ \\
\hline Average contig length (nt) & $1458(495)$ & $1773(549)$ \\
\hline Smallest contig length (nt) & $297(224)$ & $297(201)$ \\
\hline Longest contig length (nt) & $29,765(14,343)$ & $30,823(23,482)$ \\
\hline Number of ORFs & $28,433(-)$ & $31,292(-)$ \\
\hline Average ORF length (nt) & $920.28(-)$ & $841.86(-)$ \\
\hline Smallest ORF length (nt) & $297(-)$ & $297(-)$ \\
\hline Longest ORF length (nt) & $27,558(-)$ & $27,408(-)$ \\
\hline $\begin{array}{l}\text { Mapped sequenced read \% to the } \\
\text { reference assembly }\end{array}$ & 76 & 84 \\
\hline $\begin{array}{l}\text { Detected complete BUSCOs (\%) }{ }^{\mathrm{c}} \\
\text { (Arthropoda reference) }\end{array}$ & 80.6 & 82.1 \\
\hline
\end{tabular}

a represents transcript models with a predicted open reading frame (ORF); ${ }^{\mathrm{b}}$ represents transcript models without a predicted ORF; ' $\mathrm{BUSCO}$ (Benchmarking Universal Single-Copy Orthologs) v1.22 [28].

We assessed the completeness of the reference transcriptomes based on the expected presence of core genes in metazoans as identified by the BUSCO database [28]. S. frugiperda and T. $n i$ reference transcriptomes were found to have $80.6 \%$ and $82.1 \%$ expected BUSCOs, respectively, suggesting that these transcriptomes contain a core gene component comparable to those in the high quality lepidopteran genome available for silkworm [29] (Supplementary Figure S2b). Furthermore, our S. frugiperda reference transcriptome showed a better BUSCO representation than the previously published $S$. frugiperda genome and transcriptome assemblies [30,31] (Supplementary Figure S2b). Only 36\% of RNA-seq reads generated for $T$. $n i$ in our study mapped to a genome assembly recently made available for this insect [26], compared to the $84 \%$ of mapped reads to our reference transcriptome. These comparisons confirm the appropriateness of the use of our reference transcriptomes for our downstream analyses.

\subsection{Host Transcriptomic Responses to the AcMNPV Infection}

We identified 175 S. frugiperda differently expressed transcripts (DETs) and 138 T. ni DETs in response to the AcMNPV infection in hemolymph samples (Figure 2a,b). Our results represent the hemolymph samples pooled from 30 individuals 30 hours post feeding with relevant diet cubes per treatment/sample (see Methods). The DETs represent $\sim 1 \%$ S. frugiperda and $\sim 0.7 \%$ T. ni of respective reference transcriptomes. The relatively small sets of differently co-expressed genes suggest that the observed transcriptomic response pertains to an active host responding to the infection, rather than largely misregulated transcriptomes represented in a dead or a dying host overrun by the pathogen. In addition, the transcriptional responses between control and infected larvae within a host species differed minimally relative to the differences between basal transcriptomes of the two hosts (Supplementary Figure S4). The wide divergence observed in the basal transcriptomes of the two host species is not surprising, since they belong to two different genera. Our aim was to identify the common response mechanisms or pathways deduced from DETs independently detected in the two host species to the viral pathogen. In both host species, more transcripts were suppressed compared to those that were induced by viral infection (Figure 2). This is consistent with the trend observed in previous studies that investigated 
transcriptomic responses of S. frugiperda and T. ni infected with AcMNPV in cell cultures, other tissues, or other developmental stages [18-22].
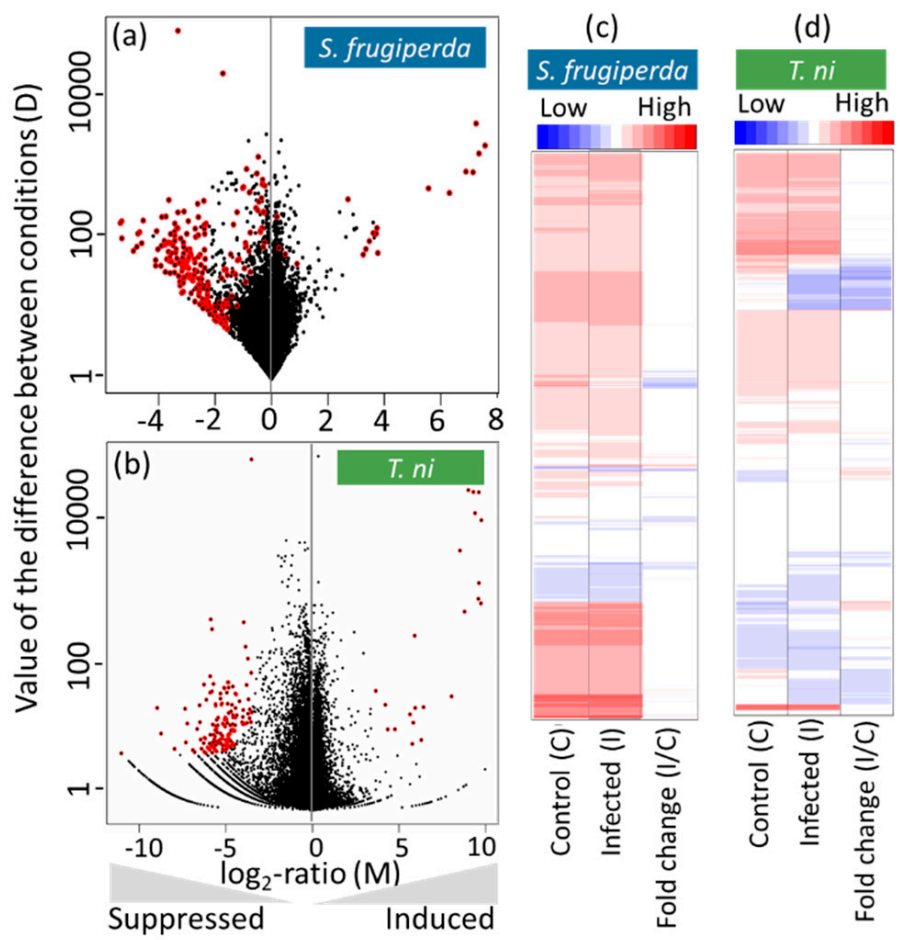

Figure 2. Host transcriptomic response to AcMNPV infection. Summary MD plots of the normalized expression values for control and AcMNPV infected samples for (a) S. frugiperda coding transcripts (18 up- and 157 down-regulated transcripts) and (b) T. ni coding transcripts (20 up- and 118 downregulated transcripts). Differently expressed transcripts (DETs) at a q-value cutoff of 0.95 are indicated in red dots and black dots, which represent non-significant transcript expression changes. All DETs with their respective fold changes are listed in the Supplementary Table S4. Heatmaps show $\log _{2}$ normalized expression of (c) 17,873 S. frugiperda and (d) 18,203 T. ni protein-coding transcripts in control and infected samples followed by fold changes in the third column. The genes are clustered based on their expression strength similarity indicated in the scale from low (blue) to high (red) normalized expression.

Overall, $83.4 \%$ S. frugiperda and $89.1 \%$ T. ni DETs could be assigned to functionally informative annotations. This was based on either functional validation of a putative homolog in D. melanogaster or a homolog reported with a putative function in another lepidopteran host. The number of Gene Ontology (GO) annotations were used when available but was more limited as GO annotations largely depended on the sequence similarity of $S$. frugiperda and T. $n i$ transcript models to a D. melanogaster gene that also had an assigned GO term. In the following sections, we highlight the shared host transcriptomic responses via enriched functional processes based on clustering of functional annotations of DETs. All DETs with functional annotations that had a fold change of 4 or more in response to the AcMNPV infection were considered. The full list of DETs and their assigned GO terms (when available) are presented in Supplementary Table S5.

\subsection{Transcripts Associated with Chitin Metabolism and Epithelial Membrane Formation and Stability Were Suppressed in AcMNPV-Infected Hosts}

The two largest enriched functional clusters out of six in S. frugiperda and the largest cluster of the two in T. ni, represented in the "suppressed" set of genes reveal a coordinated down-regulation of chitin-related genes (Figure 3). Chitin metabolism and its associated pathways are central to the formation and stability of the peritrophic matrix, cuticle, and the 
tracheal system that are in contact with the hemolymph [32]. The down-regulated genes that are associated with chitin include chitin synthase 1 (Chs1/kkv); genes encoding chitinbinding proteins especially in the peritrophic matrix (Gasp) and other genes known for their chitin associated functional roles in cuticle development such as the Osiris gene family members [33-36] (Figure 4b and Supplementary Table S4). Interrupted chitin metabolism at the cellular level is tightly coupled to the organ integrity. Drosophila chs1 mutants with suppressed expression show defective tubular structure, irregular tracheal epithelial tube expansion, and irregular subapical cytoskeletal organization [37]. The host genes serpentine (serp) and vermiform (verm) that bind to chitin and modify its surface play significant roles in the tracheal tube development [38-40] together with uninflatable (uif), which regulates tracheal growth and molting. These and many other cuticle- and tracheal growth-related genes were highly co-suppressed in infected host tissue (Figure $4 \mathrm{~b}$ and Supplementary Table S4).

\section{(a) S. frugiperda suppressed transcripts}

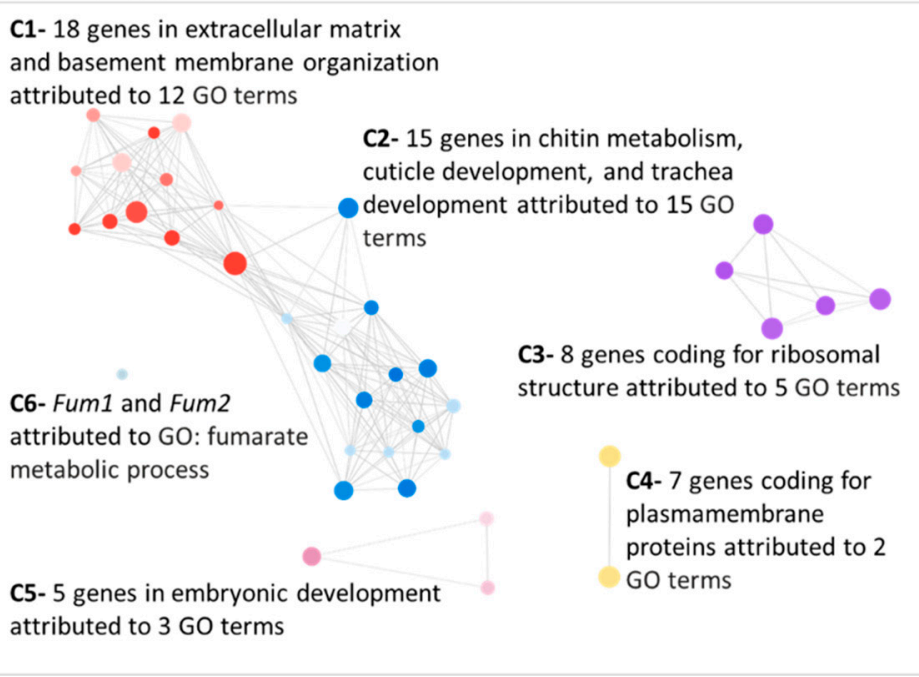

(b) T. ni suppressed transcripts

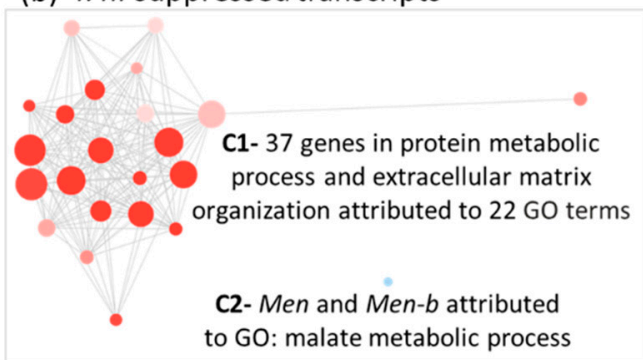

Figure 3. Overview of enriched functional processes represented by suppressed genes in the infected host transcriptomes. Functional clusters of (a) S. frugiperda and (b) T. ni transcripts suppressed upon AcMNPV infection. Each network shows GO terms, marked as nodes connected by edges that represent a minimum overlap of $80 \%$ genes (in the smaller GO term of the pair) based on Markov clustering (MCL). Distinct colors indicate shared functional groups within the network. The radius of the node represents the number of genes and the shade represents FDR adjusted $p$-value of $<0.05$ enrichment assigned using GOMCL [41]. Each cluster is named based on the largest enriched GO term in a given cluster.

The budded viruses exiting the midgut epithelial cells need to penetrate the basement membrane of the gut epithelium before entering the hemocoel and then the basement membrane of tracheal cells for systemic infections [40]. Therefore, genes associated with collagen metabolism and other integral components of the basement assembly are expected candidates for virus regulated transcriptional processes in the host. Transcripts coding for structural components of the extracellular matrix including collagen were among the most significantly suppressed in response to the AcMNPV infection in both species (Figure $4 \mathrm{~b}$ and Supplementary Table S4). We observed multiple transcripts associated with glycoproteins, likely formed in hemocytes that function in basement membrane stability, highly suppressed coordinately in both species during AcMNPV infection. Among them, laminins, osteonectins (SPARC), and papilins are notable. Laminin is the most prevalent glycoprotein in the basement membrane and is also found in extracellular matrices of tracheal cells. It is formed of three chains coded by LanA, LanB1, and LanB2 [42,43]. Notably, we found transcripts that represent all three Laminin chains to be coordinately down-regulated in the infected tissue in both species (Supplementary Table S4). SPARC, known as a $\mathrm{Ca}^{2+}$-binding extracellular glycoprotein that modulates cellular interactions with the extracellular matrix, 
was also down-regulated in both hosts (Supplementary Table S4). SPARC is particularly expressed during cellular injury or wounding that require tissue remodeling and functions in basal lamina assembly and stability $[44,45]$. Similarly, transcripts potentially coding for papilins were co-suppressed in infected samples of both hosts (Supplementary Table S4). The coordinated suppression of chitin and basement membrane associated glycoproteins in our results suggest a transcriptomic signal for weakened membrane stability in infected host tissue during the systemic infection of AcMNPV.

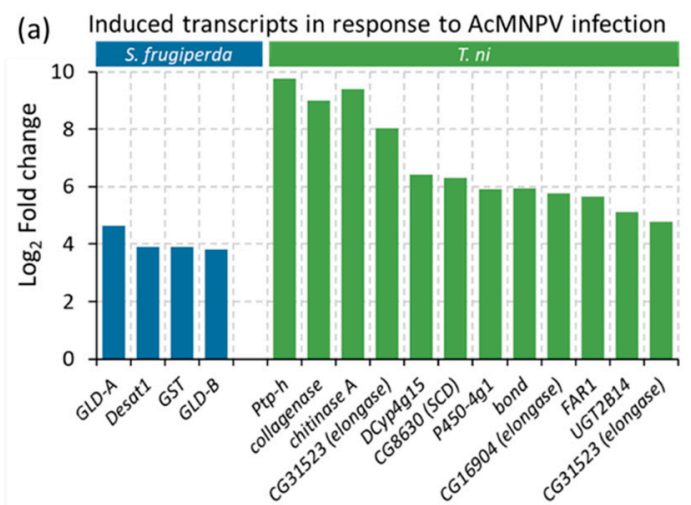

(b) Suppressed transcripts in response to AcMNPV infection

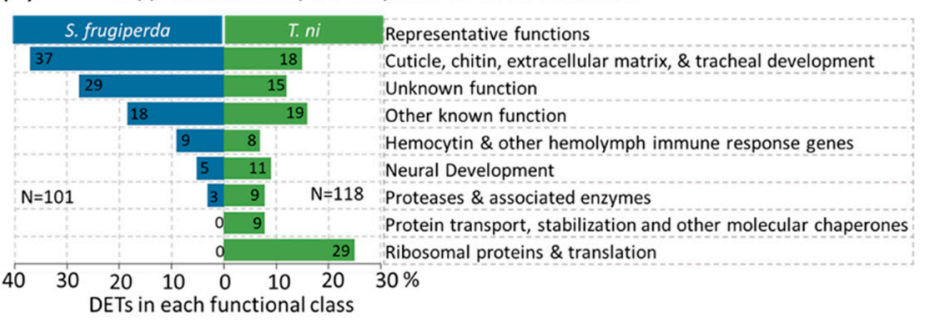

Figure 4. S. frugiperda and T. ni differently expressed transcripts (DETs) in the hemolymph in response to the AcMNPV infection. (a) Induced DETs and (b) suppressed DETs summarized based on functions to represent a total of 101 in S. frugiperda and 118 in T. ni transcripts. Log2 fold changes are calculated based on control groups within species.

\subsection{Transcripts Associated with Hemocyte-Induced Defenses and Immune Responses Were Suppressed during Systemic Infection}

Hemocytins and hemolectins were among the most highly suppressed genes in both S. frugiperda and T. ni infected samples (Figure $4 \mathrm{~b}$ and Supplementary Table S4). Membrane damage in contact with the hemocoel is sensed by hemocytes and these can initiate immune responses during pathogen invasions. Hemocytin is a key gene that mediates hemocyte aggregation and hemolymph melanization in lepidopteran innate immunity against pathogens [46-48]. Similarly, Hemolectin is specifically expressed in larval hemocytes, acts as a clotting factor, and is known to initiate immunity responses during pathogen infections $[49,50]$. Additionally, hemolymph proteases are known for their pivotal roles in defense responses against many pathogens as well as in development processes such as molting [51]. The specific regulatory pathways of many of these proteins are not definitive yet, but their collective role as a functional group in insect immunity and development are established. We found multiple proteases in both infected hosts highly suppressed as a prominent group among all suppressed transcripts (Figure $4 \mathrm{~b}$ and Supplementary Table S4).

\subsection{Lipid Metabolism and Oxidative Stress Responses Emerge as the Most Prominent Functional} Processes Induced by Both Hosts in Response to Infection

The lipid biosynthesis pathways not only affect lipid membranes, but also many other primary biological processes related to energy metabolism and signaling pathways. Interestingly, Desaturase1 (Desat1), reportedly tightly regulated at the transcriptional level [52] 
and known to be required for the biosynthesis of unsaturated fatty acids, is induced in S. frugiperda. Several other fatty acid modification enzymes, e.g., elongases such as jamesbond/bond and CYP4G, are co-induced in T. ni (Figure 4a). It is notable that bond and CG16904 together were assigned to 60 GO-terms, exemplifying their influence in multiple biological functions linked to their primary molecular functions in lipid metabolism (Supplementary Figure S5 and Supplementary Table S5).

Reactive oxygen species (ROS) generation and induction of oxidative stress are inevitable when host membranes are disrupted during host-pathogen interactions. Supportive of this expectation, all three genes induced in the infected $S$. frugiperda hemolymph in addition to Desat1 (i.e., above a four-fold expression change) relate to oxidative stress (Figure 4a). These include transcripts coding for a cytosolic GST and two FAD-glucose dehydrogenases (GLD). GSTs form a broad family of critical defense proteins against oxidative stress $[53,54]$ and $G L D$ can induce ROS generation as a defense response. Aligned with our observations, a recent study showed that GLD is induced as a defense response during AcMNPV infections in Helicoverpa zea [55].

\subsection{AcMNPV Genome Response to the Insect Hosts}

To check whether viral sequences were present in our hemolymph samples, we mapped RNA-seq reads from both species to the published AcMNPV genome [4] (Supplementary Table S2b). As expected, viral sequences were detected almost exclusively in the infected samples. We mapped $1.13 \%$ and $7.41 \%$ of total reads from infected $S$. frugiperda and T. ni samples, respectively, to the AcMNPV genome. It was interesting that a small number of reads from T. ni control samples $(<0.01 \%)$ were mapped to the AcMNPV genome (Supplementary Table S2b). While it is not conclusive that these could represent domesticated viral genes expressed at low levels in the T. ni genome, previous studies have indicated that AcMNPV genes are found in arthropod genomes as a result of horizontal gene transfer [56,57]. The difference in the percentage of mapped reads to the AcMNPV genome between two hosts is likely due to the host-specific differences. We infected both larvae at their 4th instar stage for the same amount of time before taking the hemolymph samples. Furthermore, we ranked the abundance of AcMNPV genes in both infected hosts (Supplementary Table S6). Interestingly, many of these AcMNPV genes showed similar ranks in their relative expression abundances despite being expressed in two different hosts, implying similarities in how the viral infection may be progressing in the hemolymph (Supplementary Table S6).

The AcMNPV strain E2 genome has 149 protein-coding genes [4]. We detected 148 genes in our viral transcriptome expressed in the hemolymph and Ac-IE-1/Ac147 was not expressed in both species (Figure 5a and Supplementary Table S6). Although we could not detect Ac-IE-1/Ac147 in our transcriptome data, we found both Ac-IE-0 and Ac-IE-01 were expressed (Figure $5 \mathrm{a}$ and Supplementary Table S6) that were shown to have similar functions to Ac-IE-1 in previous studies to produce the infectious virions [58,59]. Notably, Ac-IE-1/Ac147 and Ac-IE-0 share a large part of the reading frame [60] (Supplementary Figure S6). The expression of $A c-I E-1$ and $A c-I E-0$ were shown to be induced during early phase of the infection in $S f 9$ cell lines [61]. Transcripts associated with the budded virus compared to the occlusion-derived virus are reportedly more prominent during the systemic infection phase [6]. In agreement with this previous finding, we observed higher expression of viral genes related to the formation of the budded virus than those involved in the production of occlusion-derived virus (Supplementary Table S6). 

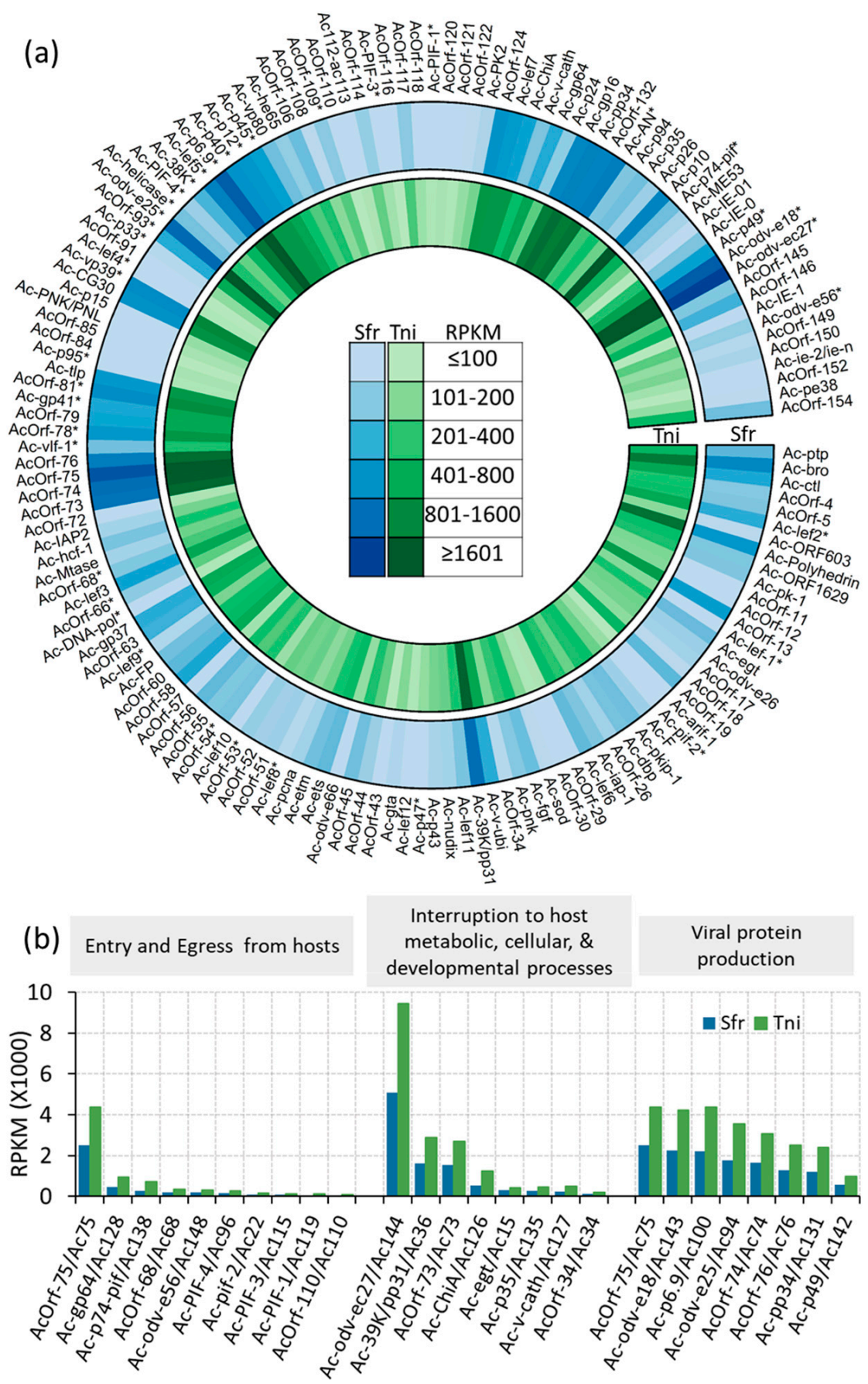

Figure 5. The AcMNPV genome expressed in the host hemolymph. (a) The circular plot shows the normalized gene expression of AcMNPV genes in infected S. frugiperda (Sfr) and T. ni (Tni) infected hosts. Core baculovirus genes are marked with asterisks. (b) Expression of AcMNPV genes associated with entry and egress from insect hosts, interruption to host metabolic, cellular, and developmental processes, and viral structural proteins.

In the infected hemolymph tissue, we found viral genes that mark both early and late stages in their expression sequence. For example, a chromatin-like structure called the virogenic stroma is formed in the center of the nucleus of infected cells. Ac36/Ac-39K/pp31 is an early viral gene reported to be among the two primary viral genes that initiates this morphological change in the host cells [62,63]. In contrast Ac74/AcOrf-74/Bm60, required for the budded virus production and also found in nucleocapsids of both budded and occlusionderived virions, is thought to be expressed at a late stage [64]. Both Ac36/Ac-39K/pp31 and 
Ac74/AcOrf-74 are among the top 10 highly expressed viral genes in infected samples of both hosts (Supplementary Table S6). The baculovirus genes are sometimes reported to be expressed as multi transcript units, but the related mechanisms or their defined borders for transcriptional units are poorly understood [20]. The majority of the highly abundant viral transcripts in our study were associated with the production of nucleocapsid and envelope proteins. Many such integral proteins of the nucleocapsid or envelope are known to function in viral entry and exit pathways (Figure 5a and Supplementary Table S6).

The viral genes affect cellular, metabolic, and developmental alterations in the host in addition to initiating viral replication and virion movement in the host cells. Some of these virus-induced host metabolic processes include host membrane degradation and developmental arrest that stops molting. The co-expressed viral genes chitinase (Ac126/Ac$C h i A)$ and cathepsin (Ac127/Ac-v-cath) are required for the liquefaction of hosts; chitinases degrade host chitins and cathepsins serve as broad-spectrum proteases that degrade host tissue [65]. Both Ac126/Ac-ChiA (found at RPKM of 540 in S. frugiperda and 1227 in T. ni) and Ac127/Ac-v-cath (found at RPKM of 236 in S. frugiperda and 494 in T. ni) were highly expressed in the infected samples in our study (Figure $5 \mathrm{~b}$ and Supplementary Table S6). This indicates a strong transcriptional signal about the extensive tissue damage initiated in the host by the virus along with the reciprocal transcriptomic signals in the hosts that suggest interrupted membrane stability during systemic infection.

Ac144/Ac-odv-ec27 is the most highly expressed AcMNPV gene (expressed at RPKM of 5081.6 in S. frugiperda and 9456.6 in T. ni) found in infected hosts in our study (Figure 5a). This is a key gene encoding a major virion structural element [66].

\subsection{Viral-Host Co-Transcriptional Interactions}

Several AcMNPV transcripts and their associated proteins are known to directly interact with host proteins to regulate pathogenicity. We wanted to assess whether such host-parasite transcript interactions could be elucidated from comparing viral transcripts co-expressed with host transcripts in the infected hemolymph. Host lipids play multifarious roles in a virus life cycle, right from the entry of the virus into host cells by endocytosis, during replication in protected membrane vesicles, and until the virions exit the cell by exocytosis. For example, host fatty acid desaturases are required for virus replication to alter the fluidity and plasticity of membranes for viral replication complexes [67]. As described earlier, host Desat1, along with several transcripts associated with fatty acid synthesis, are up-regulated in the infected hosts.

Viral entry and egress pathways highly depend on cell shape, entry and exit to the nucleus, and microvesicles regulated by host actins $[57,68]$. A late viral gene, Ac34/AcOrf-34 induces nuclear actin polymerization that promotes virus replication, and nuclear export of the virus [69-71]. In our study, Ac34/AcOrf-34 is a highly abundant viral transcript present in the hemolymph. Reciprocally, we observed a marginal induction in S. frugiperda Act57B (Supplementary Table S4). Act57B is a major myofibrillar actin gene expressed during larval stages in Drosophila and encodes a major structural protein found in the hemolymph [72]. Previous studies have reported that Ac34/AcOrf-34 directly regulates the host actin-associated Arp2/3 protein complex in the nucleus [69]. We detected a 100-fold suppression in the levels of transcripts expected to code for the Arp2/3 complex in infected T. $n i$ hosts (Supplementary Table S4). Expression of a couple of transcripts coding for zipper and cytoplasmic myosin light chain proteins, also known for their roles in regulating cell shape, was reduced by over 1800-fold in the infected T. $n i$ hemolymph (Supplementary Table S4).

Apoptosis is an important cellular process induced as a defense mechanism against viral infections by insect hosts [73]. Hcf-1/Ac70, Ac-p35/Ac135, Ac-iap-1/A27, and Ac-IAP2/Ac71 AcMNPV genes were previously described for their role in determining host tolerance to infections [73-76]. Host-cell specific factor (Hcf-1/Ac70 with normalized expression at 243.4 and 422.9 RPKM in S. frugiperda and T. ni) (Figure 5a and Supplementary Table S6) is known to be required for viral DNA replication [74]. Two cell lines of T. ni (TN-368 
and BTI-TN5B1-4) in a previous study has shown different levels of infection severity governed by $h c f-1$ [74]. The T. ni larvae infected with AcMNPV harboring a loss of function $h c p-1$ mutant allele was more tolerant compared to the wild type allele. However, similar responses were not detected when SF-21 cell lines or S. frugiperda larvae were used as viral hosts [74]. We found Ac-p35/Ac135 at similar expression levels to $h c f-1$ in both species (270.8 and 469.3 RPKM in S. frugiperda and T. ni) (Figure 5a and Supplementary Table S6). Previous studies report that $p 35$ mutated AcMNPV required higher doses of virus for LD50 when it was used to infect $S$. frugiperda, but did not show a difference in virulence when used to infect T. $n i$ [76]. The known inhibitors of apoptosis Ac-iap-1/A27 (expressed at 148.9 and 243.2 RPKM in S. frugiperda and T. ni) and Ac-IAP2/Ac71 (expressed at 229.3 and 407.2 RPKM in S. frugiperda and T. ni) also showed close to two-fold difference in relative abundance in the two hosts in our study (Figure 5a and Supplementary Table S6). Ac-IAP-1 and Ac-IAP-2 are known to inhibit apoptosis in Tn-Hi5 and Sf9 cells [27,77]. However, $S$. frugiperda and T. ni larvae infected with Ac-iap-1 loss of function AcMNPV mutant strain did not show a significant change in lethality compared to wild-type AcMNPV [78]. These may play important roles in regulating the AcMNPV infection strength in a host-specific manner in agreement with previous publications. We found reciprocal coordinated suppression of several host transcripts associated with apoptosis in infected hosts. For example, calreticulin (Calr), GDP dissociation inhibitor (Gdi), and death-related protein (Drp) were coordinately suppressed in infected T. ni hemolymph (Supplementary Table S4). Notably, the characteristic host apoptosis marker genes known for their defense were absent in the transcripts identified as significantly induced in the infected hosts. Therefore, we see a bias in the host transcriptomic signals towards an overall suppression of host apoptosis as a counter defense mechanism, favoring virus propagation (Supplementary Table S4).

AcMNPV-induced developmental arrest in the host is a known outcome in infected instars. In support of this expectation, we observed multiple host transcripts associated with larval developmental arrest. For example, the insect juvenile hormone synthesis genes, adenosylhomocysteinase and farnesyl pyrophosphate synthase, and transcripts encoding the heme peroxidase, $C y s u$, required during wing maturation, were co-suppressed in the infected S. frugiperda and T. ni hemolymph (Supplementary Table S4). Similarly, Ac15/Acegt, a highly abundant viral gene in infected hosts (RPKM of 295.8 in S. frugiperda and 433.1 in T. ni, Figure 5b and Supplementary Table S6) codes for the EGT enzyme that inactivates the insect molting hormone, ecdysone, that would lead to host developmental arrest [79].

\section{Discussion}

\subsection{Host Transcriptomic Signatures Suggest Impaired Membrane Integrity, Enabling Viral Proliferation}

Figure 6 provides an overview of genes and pathways affected by-viral interactions in the hemolymph at the systemic infection stage based on the collective deduction of our transcriptome-based analyses. Our results provide a compelling set of transcriptomic signals to support suppression of chitin-associated processes in the infected hosts, which can be linked to weakened membrane stability, as well as disrupted tracheal development during the systemic infection phase (Figure 3, Figure 4, and Figure 6). Chitin-centric processes are fundamental to the transcriptional regulation, which plays a key role in integrating various metabolic processes operating at the cell, organ, and organism levels during pathogenesis. The midgut epithelium tissue lining the hemolymph in contact with the tracheal system form the focal point for systemic infections by the budded virus $[6,80,81]$. The midgut epithelium and the tracheal system are lined by chitin and these tissues are both in contact with the hemolymph. The budded virus transiting the midgut epithelium propagate via the hemolymph and the tracheal system to cause systemic infections reaching all cells in the insect host $[6,81,82]$. The tracheoblasts, which are the smallest units in the tracheal system, are found in the hemolymph and also known to pierce the midgut basal lamina to oxygenate midgut epithelial cells. These are considered to be sites of AcMNPV secondary infection. Therefore, the midgut epithelium, basal lamina, chitin, the tracheal system, and the hemolymph play vital roles in establishing systemic infections [83-85]. 
Therefore, analyzing the transcriptional profile associated with chitin metabolism during host-pathogen interactions as suggested by [82] would be an important step in strategizing the development of baculovirus-based insecticides.

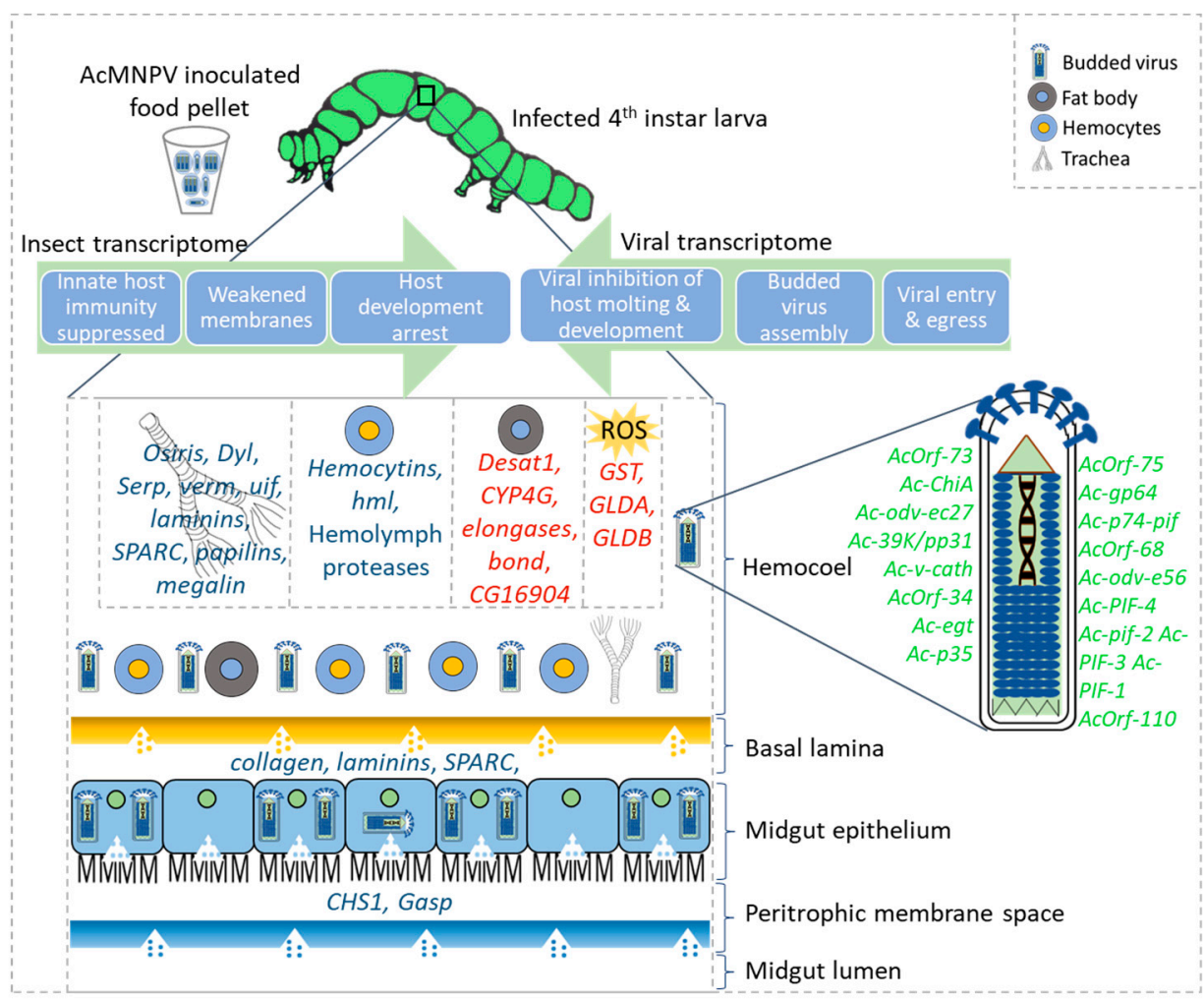

Figure 6. Overview of host and viral transcriptome responses in the hemolymph from 4th instar larvae of S. frugiperda and T. ni infected with AcMNPV. Prominent host genes that respond to the viral infection are listed in the cells/tissues most likely to express those genes. Induced genes are in red and repressed genes are in blue. Highly abundant viral genes are given in green.

Chitinases are chitin-degrading enzymes often produced by both hosts and pathogens. Insect chitinases are required for organ morphogenesis, cell division, and development [80,82]. In our current study, we did not see a significant suppression of host chitinases, except for the induction of one transcript coding for a putative chitinase in T. ni (Figure 4a). The AcMNPV genome also codes for a chitinase that disrupt the cuticle and peritrophic matrix of the insect host [86]. Chitinases coded by baculovirus genomes have a greater sequence similarity to bacterial chitinases involved in fungal chitin degradation and are distinct from insect chitinases both in sequence as well as localization in host tissues $[65,87]$. A functional viral chitinase is critical to complete the infection cycle of the AcMNPV [88]. In our study, the AcMNPV chitinase gene, Ac126/Ac-ChiA, is highly expressed in both infected hosts (Figure 5a,b, and Supplementary Table S6). It is possible that the viral chitinase transcripts, together with the cathepsin/Ac127/Ac-v-cath transcripts required for liquefaction of the host, are transcribed early on during budded virus production.

The stability of basement membranes in the host is critical in mounting a structural barrier against the movement of the virus and containing the infection. Transcripts associated with the major glycoproteins (collagen, laminin, osteonectin, and papilin), known to function in basement membrane stability, were all coordinately suppressed in both infected hosts in our study (Figure 3, Figure 4b, Figure 6, and Supplementary Table S4). Laminin and type IV collagen are the dominant glycoproteins in the basement membrane and form a stable scaffold for other glycoproteins to create a network that provides both structural and signaling support to adjacent tissues [89-93]. These glycoproteins are required for membrane assembly, and facilitate tissue remodeling after damage to the membrane. They are 
found in fat bodies, basal lamina in the basement membrane, and in the extracellular layer secreted by epithelial cells and tracheal cells $[42,45]$. The baculovirus-encoded fibroblast growth factor is known to target the laminins in the basal lamina of tracheal cells, making them more susceptible to virus movement, and thereby facilitating systemic infections [94]. Therefore, in a progressive infection, damage to the basement membrane is unavoidable. In agreement with previous studies on baculovirus infections, we observed the coordinated down-regulation of multiple transcripts coding for both stable and dynamic components of the basement membranes ( $>15 \%$ of DETs) indicative of weakened structural barriers in the host.

Massive reorganization of lipid membranes is expected as the virus escapes from midgut to the hemolymph or from the hemolymph to tracheoblasts [84,95]. A recent study by Li et al. demonstrated that fatty acid biosynthesis was reduced at early disease stages and led to the reduction of virions in S. frugiperda Sf9 cell cultures, possibly as a host defense response [96]. This supports the proposal that fatty acid synthesis is a key process that modulates viral infection levels in host cells [97]. In our study, we observed transcripts involved in fatty acid modifications strongly induced in both hosts in response to the AcMNPV infection (Figures 4a and 6). While induced host transcripts were much fewer compared to the suppressed transcripts (Figure 2a,b), it is notable that Desat1, stearoyl CoA desaturase, elongases (bond, CG31523, CG16904), and transcripts potentially coding for cytochrome P450 (CYP4G1) that collectively function in lipid biosynthesis were among the few and most induced transcripts in the infected hosts (Figure 4a). Taken both hosts together, lipid metabolism accounts for $50 \%$ of all induced DETs that were annotated with a known function (Supplementary Table S4).

Notably, Desat1, involved in unsaturated fatty acid biosynthesis, was among the most induced genes in the tobacco budworm (Heliothis virescens) hemocytes infected with Helicoverpa zea single nucleopolyhedrovirus [98]. Although it is associated with starvation-induced autophagy in Drosophila [99,100], many other integral components of the autophagy pathway known to be under transcriptional regulation [101] were not noticeably impacted in our study.

Whether host lipid synthesis genes are primarily involved in disease susceptibility or resistance is unclear. Distinguishing the specific involvement of these genes is challenging partly because of inadequate functional characterizations available for many of these genes in insect hosts. For example, in line with our results, previous studies have shown that CG16904 is induced during parasitic infections [102], but its function is unknown. Similarly, CYP4G1, a cytochrome P450 gene involved in cuticular lipid synthesis and highly conserved in insects, has been identified as the most highly expressed among 85 of CYP450 genes in Drosophila [103]. Yet, the role of CYP4G1 during viral infections has not been elucidated, despite its direct functional association with the cuticle development. It is unclear how the host defenses lead to the up-regulation of these transcripts associated with lipid synthesis specifically during viral infections concurrently with the suppression of chitin-based processes and other structural components of the basement membrane. Based on the current study from intact infected hosts and supported by previous studies using cell cultures, it is imperative that the specific role of lipid synthesis in the complex host-pathogen interactions during AcMNPV infection are comprehensively investigated.

\subsection{Hemocyte-Mediated Innate Immunity Is Suppressed during Systemic Infection}

Hemolymph is the primary target tissue we used to deduce biological processes affected by the budded virus during systemic infections. Hemocytes in the hemolymph are known to elicit innate immune responses upon pathogen infections by phagocytosis, initiate agglutination via hemolectins and other associated proteins in hemostasis, initiate melanization, or inactivate pathogens via oxidants or other antimicrobial compounds [104]. In our study, we see prominent transcript signals that suggest a suppression of the hemocyte-mediated immune responses rather than transcriptional induction of those primary genes involved. This inference is supported by the coordinated suppression of 
hemolectin and hemocytin transcripts in infected S. frugiperda and T. ni hosts together with other transcripts such as the von Willebrand clotting factor (Figures 3 and $4 \mathrm{~b}$, and Figure 6, and Supplementary Table S4).

Serine proteases and serine protease inhibitors play vital roles in hemocyte-driven phagocytosis, melanization, and antiviral immune responses in addition to their pleotropic functions in insect development $[105,106]$. The melanization reaction is tightly coupled to hemostasis reactions induced by hosts under pathogen infections as an integral part of the host immune response [46-48]. Yet, the detailed functional mechanisms of specific serine proteases in mounting defense responses against baculoviruses are poorly understood. In our study, a number of serine proteases and serine protease inhibitors were co-suppressed in both infected hosts (Figure $4 \mathrm{~b}$ and Supplementary Table S4), implying a defense response compromised by the virus in infected hosts. It should be noted that both $S$. frugiperda and T. $n i$ are known to be highly permissive hosts to AcMNPV infections [85,107]. Based on our results, the presence of the budded virus appears to strongly suppress the host immune responses initiated in the hemolymph.

3.3. Transcriptomic Signatures Indicative of Imbalances in Energy and Redox Homeostasis with Substantial Consequences to the Development of the Entire Organism during Disease Progression

Synergistic to maintaining membrane integrity via coordination of chitin and lipid metabolism, host cell survival depends on being able to maintain energy metabolism and redox homeostasis to minimize oxidative stress during infection and prevent further damage to membranes and DNA. Lavington et al. have demonstrated that a handful of enzymes in central energy metabolism can shift the flux balance and energy homeostasis [108]. Therefore, a failure to maintain homeostasis of these critical pathways suggests early signs of systemic progression of infection. We found multiple transcripts potentially coding for integral enzymes in energy metabolism and redox homeostasis suppressed in both host species by AcMNPV infection (Supplementary Table S4). These are often found to be regulated at the transcriptional levels. One such key enzyme in maintaining the redox pools and energy balance is the malic enzyme (coded by Men and Men- $b$ genes) that catalyzes malate to pyruvate while reducing NADP to NADPH $[108,109]$. It has been estimated that $30 \%$ of the total cytosolic NADPH is produced by Men in Drosophila $[110,111]$ and it is a critical enzyme in coupling energy metabolism to ROS levels under oxidative stress. Transcripts coding for the malic enzyme were suppressed with several other glycolytic transcripts in $T$. $n i$, while three out of the four significantly induced transcripts in S. frugiperda were transcripts associated with oxidative stress (Figures $4 \mathrm{a}$ and 6, and Supplementary Table S4) $[53,54,112]$.

The overall transcriptomic profiles in both infected hosts also suggest a compromised or reduced allocation of energy into critical larval development processes. We identified that a number of transcripts associated with development of wings, muscles, renal functions, and neurons in both infected hosts were significantly suppressed (Supplementary Table S4). Concurrently, we see a substantial fraction of ribosomal protein transcripts down-regulated in infected T. $n i$ implying altered rates for protein translation and overall metabolism (Supplementary Table S4). This reduction is also observed in S. frugiperda but to a lesser magnitude (less than four-fold changes) (Supplementary Table S4). Taken together, these results suggest that critical cellular and metabolic processes seem to have been significantly affected, even if only $1 \%$ of the transcriptome in the infected hosts showed significant reduction in response to the AcMNPV infection. The impaired cellular and metabolic processes consequently may affect insect development.

\subsection{Signaling Processes Associated with AcMNPV Infection}

Several studies have discovered long-chain fatty acids used in novel pheromonal signaling pathways during larval stages that lead to aggregation of individuals unlinked from pheromonal signaling in reproduction [113-117]. Desaturase1 (Desat1) is a key enzyme associated with pleiotropic effects on pheromone production and perception [118,119]. Similarly, the lipid elongase gene, bond is known for its role in conspecific signaling [90]. Desat1 
and bond are co-induced in infected hosts (Figures 4a and 6), while fatty acid biosynthesis and pheromone metabolism were among the enriched functions in response to AcMNPV infection in our study (Figure 6 and Supplementary Figure S4). The underlying genetic mechanisms of how pheromonal signaling pathways may have been exapted into a disease signaling pathway is unknown, but previous studies have confirmed the induction of these pathways in insects during viral infections $[117,120,121]$. The induction of a pheromonal pathway leading to conspecific aggregation during baculovirus infections could facilitate disease progression between individuals as non-infected larvae in close proximity to larvae that are undergoing liquefaction have a high risk in getting infected in the next disease cycle. Therefore, a pleiotropic gene such as Desat 1 is a likely candidate to be co-opted for behavioral traits evolved under an arms race between baculoviruses and their lepidopteran hosts. Alternatively, lipid synthesis genes could play a role in disease signaling systemically within the infected larvae by triggering ROS signaling [100,122]. The co-induction we observed for GST and other oxidative stress indicators (Figures 4a and 6) in S. frugiperda may further support this idea of the involvement of ROS pathways in disease signaling.

\subsection{The Role of AcMNPV Genes Found in the Host Hemolymph}

The AcMNPV protein-coding genes regulate host cellular and physiological processes as well as the production of the two distinct types of enveloped virions: the occlusionderived virions and the budded virions [123]. Our viral transcript quantification suggests that the budded virions are more abundant than occlusion-derived virions in infected hemolymph samples (Figure 5a and Supplementary Table S6), an observation also supported by previous studies [6]. The transcriptomic signature of the eukaryotic host genome is overrepresented compared to the viral genome expressed in our RNA samples that capture the host-pathogen interactions. Yet, the specific quantification of transcripts made feasible with RNA-seq data allows the detection of clear biological signals from the virus in host tissue (Figures 1 and 5a, and Supplementary Table S6).

Baculoviruses arrest the molting of infected lepidopteran larvae [123]. This process is primarily governed by the ecdysteroid UDP-glucosyltransferase (EGT), a viral enzyme that inactivates the insect molting hormone, ecdysone [79]. Ac15/Ac-egt in the AcMNPV genome codes for EGT. In our study, Ac15/Ac-egt is among the most highly expressed viral transcripts found in the infected hemolymph of S. frugiperda and T. ni (Figures $5 \mathrm{~b}$ and 6 , and Supplementary Table S6). Previous studies have reported higher EGT activities in the hemolymph compared to other tissue [124]. Hoover et al. demonstrated the role of EGT on the climbing behavior of gypsy moth larvae [125]. Subsequent studies have confirmed the role of EGT in influencing behavioral traits of other hosts including T. ni and Spodoptera exigua $[126,127]$. However, much of the genetic basis is unknown for these behavioral traits and at least in Spodoptera hosts, EGT alone is reported to be insufficient to elicit behavioral traits [126]. Therefore, the role of virus-induced behavioral effects on lepidopteran hosts remains a topic of interest at large.

3.6. Host Transcriptional Responses to the Budded Virus during the Systemic Infection Stage Differs from the Midgut Responses to the Occlusion-Derived Virus during the Primary Infection Stage

Shrestha et al. described the host transcriptomic landscape of the midgut during the primary infection phase of AcMNPV in $T$. $n i$ th instar larvae primarily caused by the occlusion-derived virus [22]. The current study that focusses on the systemic infection stage predominantly caused by the budded virus in 4th instar larvae of two lepidopteran hosts including T. ni depicts a very different host transcriptomic landscape. The most consistently up-regulated transcripts (at least 16-fold) observed in the midgut in the study by Shrestha et al. included REPAT (REsponse to PAThogens), Atlastin (involved in ER and vesicle trafficking), cyclic GMP-AMP synthase (cGAS) genes that can bind to cytosolic viral DNA, Ubiquitin-ligase-3 SIAH, a zinc finger CCHC, a peroxidase, and a chymotrypsin-like serine protease [22]. None of these transcripts were found to be significantly expressed in response to the infection in the infected hemolymph in our study. An earlier study 
had shown increased REPAT in the midgut of baculovirus infections of Spodoptera exigua larvae [128] similar to the observations made by Shrestha et al. for T. ni [22]. These previous observations and the absence of significant changes to these transcripts in the hemolymph during systemic infections imply that these host transcripts may be specific to the infection phase or tissue. There is a clear transcriptomic signal given by multiple key apoptosisrelated genes induced in the infected midgut of T. ni, as reported by Shrestha et al. [22]. While we do not observe the induction of the same transcripts in our study, several other apoptosis-related genes were suppressed in the infected hemolymph during systemic infections (Figure 6).

For certain time points post-infection in the midgut, Shrestha et al. reported upregulation for several cuticle-related transcripts [22]. The transcriptomic signal associated with cuticle-proteins are likely stemming from tracheaoblasts in the hemolymph in our study, contrasting the transcripts reported by Shrestha et al. likely coding for cuticleproteins affected in the peritrophic matrix lining the midgut during the occlusion-derived virus propagation [22]. The invasion of the budded virus into the tracheal epidermis is essential to the progression of the systemic infection as the host cannot shed these cells, unlike the gut epithelium infected by the occlusion-derived virus that can be shed as seen in semi permissive hosts [85]. This may explain why we observe exceedingly more transcripts potentially coding for cuticle, chitin, and associated membrane processes clearly suppressed as a result of successful disease progression than in infected midgut cells reported by Shrestha et al. [22].

The most notable consistently down-regulated genes (by at least 16-fold), during the occlusion-derived virus invasion of the midgut, mainly included orthologs of flippase and genes coding for a number of Cytochrome P450 enzymes, serine proteases, calcium binding protein $\mathrm{P}$, and dehydroecdysone 3 alpha-reductase, as noted by Shrestha et al. [22]. None of these were significantly changed during the budded virus infection in either host in the current study. While there was hardly any direct overlap of down-regulated transcripts between the primary-midgut infection and the secondary-systemic infection, we see melanization as a suppressed pathway in both studies. Shrestha et al. described the down-regulation of serine proteases involved in the melanazation cascade similar to our observation for the suppression of multiple serine proteases thought to be involved in melanization and other defense responses (Figure 5b) [22]. Contrasting the overall observations made by Shrestha et al. during the midgut infection, the hemolymph of both hosts in our study during systemic infection appear to clearly induce transcripts associated with oxidative stress while suppressing those related to hemostatis, chitin metabolism, and tracheal development [22].

\subsection{Key Host Genes Affected by the AcPNMV Infection Are Targets of Commercially Available Pesticides Used against Lepidopteran Pests}

The commonly targeted host genes by the viral pathogen include CHS1, and transcripts associated with actin driven cellular functions as well as genes involved in insect hormone regulation. It is interesting to note that many of the chemical insecticides also use the same genes as primary targets to control lepidopteran pests. However, unlike chemical insecticides, baculoviruses continue to spread in the field post-host liquification.

Many insecticides target chitin biosynthesis as a more specific and safer alternative to generic insecticides such as pyrethroids and organophosphates. These chitin synthesis inhibitors largely include the benzoylphenylurea (BPU) group of insecticides, oxazolines, tetrazines, thiadiazines, thiazolidines, and triazines $[129,130]$. All chitin biosynthesis inhibitors act on chitin synthesis at various stages of the complex biochemical pathways, leading to the interruption of chitin production and cuticle development. The BPUs are shown to target CHS1 to inhibit chitin metabolism early in the biosynthesis pathway [131]. Notably, CHS1/kkv is the main chitin synthase required for epicuticular stability, intact procuticle, maintenance of epidermal morphology, and sclerotization and pigmentation of the cuticle [132]. A number of genes associated with chitin synthesis and cuticle modifications 
(discussed earlier) are among the most highly suppressed transcripts in both hosts during systemic infection.

Pyridalyl is another commonly used potent insecticide against lepidopteran pests [131]. It has been used to control fall armyworm outbreaks in South Africa [133,134]. The molecular mechanism of pyridalyl generates excessive amounts of ROS, which eventually leads to severe oxidative stress and cell death in lepidopterans [135]. Among the handful of strongly induced genes during systemic infections, GST and other genes associated with oxidative stress are notable (Figures $4 \mathrm{a}$ and 6). Further induction of these oxidative stress pathways disproportionately divert energy to oxidative stress responses that could expedite cell death and, in turn, host death. The current observation made in our study further supports the insecticidal potential of AcMNPV strains selected to induce host oxidative stress responses similar to observations made with pyridalyl activity.

Double stranded RNAs (dsRNAs) that mimic insect transcripts have emerged as a powerful tool for targeted pest control. For example, dsRNAs of actin transcripts used as foliar sprays have shown to be a promising insecticide for Colorado potato beetles that damage multiple Solanaceae crops [136]. In line with our findings made in the current study, baculoviruses are known to target actin-mediated cellular processes [68]. Actin is present in all cells and customization to target-specific lepidopteran actins or a regulatory gene of actin-mediated processes is equally achievable with baculoviruses. Transcript-level inhibition of the juvenile hormone biosynthesis or alterations to its regulation is another target attempted in recombinant baculoviruses developed as potential biopesticides $[137,138]$. Host genes associated with juvenile hormone regulation were noticeable among suppressed transcripts in infected T. ni in our study similar to previous observations made when wild type AcMNPV strains were used [139]. Importantly, baculoviruses are more effective as delivery agents in controlling host genes than the passive delivery methods available for dsRNA-based insecticides [140]. The use of recombinant baculovirus strains to control pests has been proposed for decades and has recently gained more attention as sustainable biopesticides [141-143].

\section{Material and Methods}

\subsection{Insect and Virus Source Material}

Given the natural progression of an epizootic in the field and the need to collect a considerable amount of hemolymph for the transcriptome analysis, we used 4th larvae in the experiments outlined below. S. frugiperda and T. $n i$ were obtained as eggs from Benzon Research Inc. (Carlisle, PA, USA). Once the eggs hatched, we reared them in individual oneounce cups on an artificial diet (Southland Products Inc., Lake Village, AR, USA) at $28.9^{\circ} \mathrm{C}$ and a 16 hour-light and 8 hour-dark cycle until they reached the 4th instar. Wild-type AcMNPV strain E2, which was used in this study, was field collected. To amplify the virus for the experiment, the virus was passed through Chrysodeixis includens, the soybean looper.

\subsection{Determination of LD95 of AcMNPV for S. frugiperda and T. ni}

We used a standard dose-response protocol and Bayesian analysis to quantify the lethal dose at which $95 \%$ of the larvae would be expected to succumb to viral infection or the LD95. For the experiment, 30 recently molted 4 th larvae, which were starved for $24 \mathrm{~h}$, were fed a known amount of virus on a small diet cube. The virus was suspended in a $3 \mu \mathrm{l}$ droplet of deionized water. One set of larvae was used as a control and consumed a diet cube that had been only inoculated with $3 \mu$ ls of deionized water. None of the controls became infected. Only larvae that consumed the entire diet cube were used in the experiment to ensure that the larvae received a full dose of the virus. Viral doses varied depending upon the species (Figure 1). After consuming the diet cube, larvae were placed in one-ounce cups and reared until pupation or death. Death resulting from AcMNPV infection was confirmed either by host liquefaction in the diet cup or by examining the hemolymph under a light microscope [8]. For T. ni, the experiment was conducted twice, since the first set of experiments used doses that were too high resulting in almost $100 \%$ mortality and, thus, 
making it difficult to estimate the LD95. The second set of experiments used much lower doses. We combined the data from the two experiments for the T. ni dose-response analysis.

To analyze the data, we used a Bayesian framework with vague priors to fit a logistic regression model [144] for each species. The associated slope and intercept of the fitted model was used to calculate the LD95. All analyses were conducted in R [145] using the JAGS [146] and the R2JAGS packages [147]. For each analysis, three chains were run from different starting points. The first 10,000 draws from the Bayesian Markov chain Monte Carlo (MCMC) were removed to account for transient dynamics at the start of the chain. The remaining 90,000 draws were retained to estimate the parameters of the logistic regression. All non-discarded draws were retained to ensure precise parameter estimates [148]. After a visual inspection of the chains for convergence, multiple tests were used to ensure that the chains had converged including the Gelman-Rubin and the Hiedelberg-Welch tests [149]. The chains for each analysis were combined to form a posterior distribution. Additionally, we conducted a posterior predictive check to test whether the predicted model fit the data collected [150]. As part of the posterior predictive check, Bayesian $p$-values were calculated. Values near 0.50 indicate that the model fits the data reasonably well [151]. The Bayesian logistic regression for both species passed each of the individual tests outlined above.

\subsection{Insect Treatment with AcMNPV Virus}

Using the LD95 calculated from the dose-response experiments, 4th instar larvae from both species were fed the appropriated dose of virus (S. frugiperda, $10^{4.5}$ occlusion bodies T. $n i, 10^{3}$ occlusion bodies) in a diet cube using the same method as the dose-response experiment. Control larvae were fed a diet cube inoculated with deionized water. After 30 hours, 30 individuals per sample were used to extract the hemolymph.

\subsection{Extraction of Hemolymph and Preparation of RNA-Seq Libraries}

Prior to hemolymph extraction, each individual was chilled to ease the extraction process. A pre-chilled microcentrifuge tube was filled with a $25 \mu \mathrm{L}$ solution containing 10 units of RNAseOut (Invitrogen, Carlsbad, CA, USA) in a $0.1 \%$ PTU dissolved in a PBS solution. The rear proleg of the 4th instar larva was then cut with micro scissors. We collected hemolymph from the wound and pipetted the hemolymph into a pre-chilled Eppendorf tube (USA Scientific, Inc., Ocala, FL, USA). The solution was then vortexed, immediately placed in a dewar filled with liquid nitrogen, and stored at $-80{ }^{\circ} \mathrm{C}$ until needed. Given that the previous publication has reported that the hemolymph contains occlusion bodies in a relatively short time post infection [152], we extracted the hemolymph and used it for our transcriptome analysis. The hemolymph includes hemocytes as the major blood cell type. Other cell types, including tracheoblasts, midgut epithelial cells, fat bodies, nerve, muscle, and other epithelial cells lining internal organs, are immersed or in contact with the hemolymph and can release proteins, metabolites, and transcripts into the cell-free fraction of the hemolymph. We discarded any hemolymph sample that had visible tissue contamination when drawing it from larvae but expect to see transcripts from the above sources in the RNAseq analyses of the hemolymph.

Total RNA was isolated from hemolymph samples using RNeasy Mini Kit (Qiagen, Hilden, Germany). On-column DNase digestion was carried out with the RNase-free DNase Kit (Qiagen, Hilden, Germany), followed by a further purification step using RNeasy Mini Spin Columns (Qiagen, Hilden, Germany). The quantity, quality, and integrity of the total RNA was sequentially assessed using the A260/A280 values reported with a Nanodrop spectrophotometer (Thermo Scientific, Wilmington, DE), agarose gel (Agarose unlimited ${ }^{\mathrm{TM}}$, Gainsville, FL, USA) electrophoresis, and a BioAnalyzer (Agilent Technologies, Inc., Santa Clara, CA, USA).

RNA-seq library preparation and sequencing were done at the University of Illinois at Urbana-Champaign Roy J. Carver Biotechnology Center. Ribosomal RNA (rRNA) depletion was performed on the RNA samples using the RiboZero kit (Illumina, San Diego, 
CA, USA) following the manufacturer's instructions. Capturing polyA-enriched RNA from total RNA is a more customary approach for eukaryotic RNA-seq experiments. However, we decided to use rRNA depleted samples because we planned to identify both insect and viral transcripts which may not always contain $3^{\prime}$ polyA sequences. The rRNAdepleted samples were used for TruSeq Stranded RNA Sample Prep kit to produce $5^{\prime}$ to $3^{\prime}$ strand-specific cDNA libraries (Illumina, San Diego, CA, USA). A TruSeq SBS sequencing kit version 3 (Illumina, San Diego, CA, USA) was used following the manufacturer's instructions to generate the sequencing libraries. All libraries were pooled, barcoded, and multiplexed on two lanes of an Illumina HiSeq2000 platform (Illumina) to run for 101 cycles. Randomly selected reads of 100 nucleotide lengths from each library were processed and demultiplexed with Casava 1.8.2, which generated over 370 million reads with quality scores over 30 .

\subsection{Sequencing, Assembly, and Annotation of the Reference Transcriptome}

To allow accurate identification of host transcripts from two species, we needed to create two reference transcriptomes for the hemolymph of 4th instar caterpillars. RNAseq reads were processed to generate a reference transcriptome assembly and annotation following a custom pipeline published previously [153]. Briefly, raw Illumina reads were subjected to quality checks using FastQC and de novo assembled using Trinity v2.2.0 [154] using default parameters. Contigs with low read support, contaminants, and artifacts were removed as described in Oh et al. [155]. We further clustered contigs showing $>95 \%$ sequence identity over $>70 \%$ of total contig length of the shorter contig in each pairwise alignment, using CD-HIT-EST v4.6 [156] to minimize redundancy. For each cluster, the transcript with the longest open reading frame (ORF), predicted by Transdecoder v2.0.1 (https://transdecoder.github.io/), was selected as a representative transcript model in the final protein-coding reference transcriptome. The completeness of each reference transcriptome assembly was evaluated using Benchmarking Universal Single-Copy Orthologs (BUSCO) database v2.1 [28] with the metazoan dataset (metazoa_odb9) and default settings. BUSCO looks for the presence of the conserved single copy orthologs in the selected lineage, which we chose as metazoans, which included 65 species. A series of sequential BLAST searches found the best possible annotation for both coding and non-coding transcript sequences, using the NCBI Drosophila mRNA database, NCBI-insects-reference RNA (refseq_rna), and NCBI-non redundant (nr) databases for all eukaryotic proteins and RNA, with a maximum e-value cutoff of $10^{-5}$.

An ideal transcriptome is expected to consist of all expressed genes in a given condition. This would include both coding and non-coding transcripts. However, the non-coding transcript pool is highly incomplete even for the premier model species. Therefore, it would be impractical to assign reasonable functional annotations for contigs that may represent true non-coding transcripts in our study. Additionally, without any canonical structural features to use in assessing the completeness of non-coding transcripts, those transcripts could also contain a highly fragmented fraction of the assembly. Therefore, we divided our assembled transcriptome into coding and non-coding reference transcriptomes and only used the protein-coding transcriptome for our current analyses. Despite the lack of resources to fully annotate putative non-coding transcripts, this pool of non-coding transcripts likely represents a genetic component that has potential to be useful as a collective resource from diverse species as more high throughput data-driven projects are conducted. Therefore, we include Table 1 and Supplementary Figure S1, where we report a total of 101,169 and 147,772 processed non-coding transcripts, with a mean length of 495 and 549nt, for S. frugiperda and T. ni, respectively, as an additional molecular resource included in our data deposit to NCBI BioProject PRJNA664633.

The protein-coding reference transcriptome was used for the downstream RNA-seq analysis. Each sequence used as a proxy to represent gene/transcript models in our study when assessing biological processes is designated by its gene name, followed by the shortened form of the gene name (if available), the sequence ID given by our annotation 
process, and the FlyBase or NCBI accession number used for its annotation as shown in Supplementary Table S4. The highly abundant or regulated genes discussed in our study are listed in Supplementary Table S7 with references that describe their molecular function.

\subsection{RNA-Seq Analysis}

The goal of our experiment was to search for shared disease responses inferred from the two host species affected by AcMNPV infection using three sets of biologically independent RNA-seq datasets. Two datasets were from S. frugiperda and one set was from T. ni. The RNA-seq reads were aligned to the relevant reference transcriptome using bowtie [157] with a seed alignment length per read set to $50 \mathrm{nt}$. Reads unambiguously mapped to each gene model were counted using a custom python script to generate read-count values as a proxy for gene expression. We used NOISeq [158] with a q-value cutoff of $\geq 0.95$ to identify transcripts differently expressed between control and AcMNPV-infected samples in both insect species. Gene ontology (GO) terms enriched among differently expressed transcripts (DETs) were detected using BiNGO [159] at a false discovery rate (FDR) adjusted $p$-value $<0.05$ [159]. We used the entire reference protein-coding transcriptomes as custom backgrounds to test for functionally enriched clusters when inferring the shared biological processes identified from each host species. GO annotation of reference protein-coding transcriptomes for the two insect species was based on sequence similarity compared to Drosophila melanogaster gene models that have assigned GO terms. We used GOMCL [41] to identify the non-redundant functional clusters from the primary set of enriched functions generated using BINGO for each species.

To assess the transcripts originating from the viral genome, particularly in the infected samples, RNA-seq reads were mapped to the AcMNPV reference genome gene models [4] using bowtie [157]. The read counts mapped to the viral genome were normalized by converting to RPKM values (Reads Per Kilobase Million) for each viral gene expressed in the insect transcriptomes. Total read counts were calculated by adding the reads mapped to the viral genome and insect gene models for control and AcMNPV infected samples as used in a previous study [160].

\section{Conclusions}

We identified an extensive overlap between biological processes that were represented by differently expressed transcript in 4th instar larvae of two hosts, S. frugiperda and T. ni, in response to the systemic infection of AcMNPV as well as convergence in the ranked abundance of viral genes expressed in the two hosts. The overall host transcriptomic signals suggested chitin-associated processes and membrane integrity were compromised together with immune responses in infected hosts. Our results suggest that oxidative stress indicators, moderately induced by the viral infection, may play a role in systemic disease signaling with the induction of selected classes of fatty acids (Figure 6). The entire core viral genome was detected during the systemic infection phase in both hosts, with a bias towards transcripts primarily associated with the budded form of the virus. The hostvirus interactions deduced from co-expressed host and viral transcripts indicate an overall transcriptomic landscape overwhelmed by viral counter defenses that facilitate disease progression. The specific transcripts and the convergent biological processes, highlighted in our study as highly affected during infections, identify key genes and pathways as potential molecular targets that may contribute to designing recombinant AcMNPV strains as molecular tools in sustainable pest management.

Supplementary Materials: The supplementary materials are available online at https:/ /www.mdpi. com/article/10.3390/ijms22073568/s1. Figure S1. Assembled contig length frequency distribution for S. frugiperda and T. ni reference transcriptomes. [a] Coding contigs and [b] non-coding contigs. Comparison of average CDS length [c] and number of protein coding transcripts [d] between $S$. frugiperda and T. ni compared to B. mori, H. armigera, S. litura, and the T. ni genome. Figure S2. Quality assessments of $S$. frugiperda and T. ni reference transcriptomes. [a] proportions of different ORF types and $[b]$ assembly completeness of the references created in this study compared to the previously 
published S. frugiperda draft genome and transcriptomes (Kakumani et al. 2014 and Legeai et al. 2014) assessed using BUSCO. Figure S3. Annotation summary of the S. frugiperda and T. ni transcriptome assembly for coding transcripts. Functional annotation of reference transcriptome was performed using sequential BLAST with an e-value cutoff $10^{-5}$ searched within the Drosophila mRNA database, insect reference RNA (refseq_rna) database, and non-redundant (nr) database. The annotations of reference transcriptome for both species are provided in the Supplementary Table S3. Figure S4. Principal component analysis (PCA) of ortholog gene pairs between S. frugiperda and T. ni. Figure S5. Clustered enriched functional processes among induced T. $n i$ transcripts upon AcMNPV infection. The full list of enriched GO terms and GOMCL cluster output are included in the Supplementary Table S5. Figure S6: Amino acid sequence alignment of Ac-IE-1/Ac147, Ac-IE-0, and Ac-IE-01. Ac-IE-1 shows high similarity to $A c-I E-01$ except for the 54 amino acids in the amino terminus end of $A c-I E-01$. The sequence alignment was performed with CLUSTAL O (1.2.4). Previously known Ac-IE-01 is annotated as Ac-IE-0 and previously known Ac-IE-0 is annotated as Ac-IE-01 in the AcMNPV genome clone C6, gene bank accession number: L22858 (Ayres et al., 1994) and AcMNPV E2 genome: gene bank accession number: KM667940 (Maghodia et al., 2014). Table S1. RNAseq data generated for each sample. Table S2. [a] Summary of short reads mapped to S. frugiperda and T. ni reference transcriptomes and $[\mathrm{b}]$ percentage of short reads mapped to the AcMNPV viral genome (Maghodia et al. 2014) for control and AcMNPV treated samples. Table S3. Annotation of transcript models with predicted ORFs for $S$. frugiperda and T. ni transcriptome assembly. Table S4. List of DETs for $S$. frugiperda and T. $n i$ in response to AcMNPV infection. Table S5. Gene ontology enrichment analysis for DETs for S. frugiperda and T. ni. Table S6. Reads associated with AcMNPV genes mapped to S. frugiperda and T. ni control and infected samples. Table S7. References to molecular functions associated with genes highlighted in our analysis.

Author Contributions: M.D. and B.D.E. designed the experiment; B.D.E. conducted the dose response test of the host species, raised the larvae in the control and infected groups, and extracted hemolymph samples; S.C. extracted RNA and optimized methods to obtain high quality RNA to be used for RNA-seq libraries; P.P. conducted the bioinformatics analysis and data curation; P.P. and M.D. developed the bioinformatics analyses, interpreted data, and wrote the manuscript; D.-H.O., S.C. and B.D.E. assisted with data interpretation and provided feedback. All authors have read and agree to the published version of the manuscript.

Funding: This project was funded by a grant from the USDA Agriculture \& Food Research Initiative Competitive [grant no. 2019-67014-29919/project accession no. 1019862] as part of the joint USDANSF-NIH-BBSRC-BSF-NNSFC Ecology and Evolution of Infectious Diseases program to B.D.E. and M.D., the National Science Foundation award MCB 1616827, and the Next-Generation BioGreen21 Program of Republic of Korea (PJ01317301) to M.D. and D.H. P.P. was supported by an Economic Development Assistantship award from Louisiana State University. The funding bodies played no role in the design of the study and collection, analysis, and interpretation of data and in writing the manuscript.

Institutional Review Board Statement: Not applicable.

Informed Consent Statement: Not applicable.

Data Availability Statement: The Illumina RNA-Seq reads from this article have been deposited to the NCBI sequence read archive (SRA) database, the assembled transcriptome is available in transcriptome shotgun assembly (TSA) database, and the expression profile is available at gene expression omnibus (GEO) under the accession number for NCBI BioProject ID: PRJNA664633.

Acknowledgments: The authors thank the High Performance Computing at the Louisiana State University (HPC@LSU) for providing computational resource for data analysis, the Louisiana State University Library services for aiding with retrieving articles via interlibrary loans, Forrest Dillemuth for rearing larvae, and Chathura Wijesinghege and Prava Adhikari for their art work in the illustration.

Conflicts of Interest: The authors declare no conflict of interests.

\section{References}

1. Fuxa, J.R. Prevalence of viral infections in populations of fall armyworm, Spodoptera frugiperda, in Southeastern Louisiana. Environ. Entomol. 1982, 11, 239-242. [CrossRef] 
2. Miller, L. The Baculoviruses; Miller, L.K., Ed.; Kluwer Academic: Dordrecht, The Netherlands, 1997.

3. Ayres, M.D.; Howard, S.C.; Kuzio, J.; Lopez-Ferber, M.; Possee, R.D. The compelete DNA sequence of Autographa californica nuclear polyhedrosis virus. Virology 1994, 202, 586-605. [CrossRef]

4. Maghodia, A.B.; Jarvis, D.L.; Geisler, C. Complete genome sequence of the Autographa californica multiple nucleopolyhedrovirus strain E2. Genome Announc. 2014, 2, 6-7. [CrossRef] [PubMed]

5. Hu, Y.C. Baculovirus vectors for gene therapy. Adv. Virus Res. 2006, 68, 287-320. [CrossRef] [PubMed]

6. Blissard, G.W.; Theilmann, D.A. Baculovirus entry and egress from insect cells. Annu. Rev. Virol. 2018, 5, 113-139. [CrossRef] [PubMed]

7. Elderd, B.D. Developing models of disease transmission: Insights from the ecology of baculovirus-driven systems. PLoS Pathog. 2013, 9, e1003372. [CrossRef] [PubMed]

8. Cory, J.S.; Myers, J.H. The ecology and evolution of insect baculoviruses. Annu. Rev. Ecol. Evol. Syst. 2003, 34, 239-272. [CrossRef]

9. Haas-stapleton, E.J.; Washburn, J.O.; Volkman, L.E. Pathogenesis of Autographa californica M nucleopolyhedrovirus in fifth instar Spodoptera frugiperda. J. Gen. Virol. 2003, 2033-2040. [CrossRef] [PubMed]

10. FAO and CABI Community-based fall armyworm (Spodoptera frugiperda) monitoring, early warning and management. In Training of Trainers Manual, 1st ed.; FAO: Rome, Italy, 2019; ISBN 9789251312315.

11. Mota-Sanchez, D.; Wise, J.C. The Arthropod Pesticide Resistance Database; Michigan State University: East Lansing, MI, USA, 2020; Available online: www.pesticideresistance.org (accessed on 31 July 2020).

12. Wang, P.; Zhao, J.Z.; Rodrigo-Simón, A.; Kain, W.; Janmaat, A.F.; Shelton, A.M.; Ferré, J.; Myers, J. Mechanism of resistance to Bacillus thuringiensis toxin Cry1Ac in a greenhouse population of the cabbage looper, Trichoplusia ni. Appl. Environ. Microbiol. 2007, 73, 1199-1207. [CrossRef]

13. Lindgren, P.D.; Greene, G.L. Suppression and mAnagement of Cabbage Looper Populations; USDA Technical Bulletin: Washington, DC, USA, 1984.

14. Sparks, A.N. Review of the biology of the fall armyworm (Lepidoptera, Noctuidae). Fla. Entomol. 1979, 62, 82-87. [CrossRef]

15. Richter, A.R.; Fuxa, J.R.; Abdel-Fattah, M. Effect of host plant on the susceptibility of Spodoptera frugiperda (Lepidoptera: Noctuidae) to a nuclear polyhedrosis virus. Environ. Entomol. 1987, 16, 1004-1006. [CrossRef]

16. Pitre, H.N.; Hogg, D.B. Development of the fall armyworm (Lepidoptera, Noctuidae) on cotton, soybean and corn. J. Georg. Entomol. Soc. 1983, 18, 182-187.

17. Shorey, H.H.; Andres, L.A.; Hale, R.L. The biology of Trichoplusia ni (Lepidoptera: Noctuidae). I. life history and behavior. Ann. Entomol. Soc. Am. 1962, 55, 591-597. [CrossRef]

18. Salem, T.Z.; Zhang, F.; Xie, Y.; Thiem, S.M. Comprehensive analysis of host gene expression in Autographa californica nucleopolyhedrovirus-infected Spodoptera frugiperda cells. Virology 2011, 412, 167-178. [CrossRef] [PubMed]

19. Wei, L.; Cao, L.; Miao, Y.; Wu, S.; Xu, S.; Wang, R.; Du, J.; Liang, A.; Fu, Y. Transcriptome analysis of Spodoptera frugiperda 9 (Sf9) cells infected with baculovirus, AcMNPV or AcMNPV-BmK IT. Biotechnol. Lett. 2017, 39, 1129-1139. [CrossRef]

20. Chen, Y.-R.; Zhong, S.; Fei, Z.; Hashimoto, Y.; Xiang, J.Z.; Zhang, S.; Blissard, G.W. The transcriptome of the baculovirus Autographa californica multiple nucleopolyhedrovirus in Trichoplusia ni cells. J. Virol. 2013, 87, 6391-6405. [CrossRef] [PubMed]

21. Chen, Y.-R.; Zhong, S.; Fei, Z.; Gao, S.; Zhang, S.; Li, Z.; Wang, P.; Blissard, G.W. Transcriptome responses of the host Trichoplusia $n i$ to infection by the baculovirus Autographa californica multiple nucleopolyhedrovirus. J. Virol. 2014, 88, 13781-13797. [CrossRef]

22. Shrestha, A.; Bao, K.; Chen, W.; Wang, P.; Fei, Z.; Blissard, G.W. Transcriptional responses of the Trichoplusia ni midgut to oral infection by the baculovirus Autographa californica Multiple Nucleopolyhedrovirus. J. Virol. 2019, 93, e00353-19. [CrossRef]

23. Xia, Q.; Zhou, Z.; Lu, C.; Cheng, D.; Dai, F.; Li, B.; Zhao, P.; Zha, X.; Cheng, T.; Chai, C.; et al. A draft sequence for the genome of the domesticated silkworm (Bombyx mori). Science 2004, 306, 1937-1940. [CrossRef]

24. Pearce, S.L.; Clarke, D.F.; East, P.D.; Elfekih, S.; Gordon, K.H.J.; Jermiin, L.S.; McGaughran, A.; Oakeshott, J.G.; Papanikolaou, A.; Perera, O.P.; et al. Genomic innovations, transcriptional plasticity and gene loss underlying the evolution and divergence of two highly polyphagous and invasive Helicoverpa pest species. BMC Biol. 2017, 15, 1-30. [CrossRef]

25. Cheng, T.; Wu, J.; Wu, Y.; Chilukuri, R.V.; Huang, L.; Yamamoto, K.; Feng, L.; Li, W.; Chen, Z.; Guo, H.; et al. Genomic adaptation to polyphagy and insecticides in a major East Asian noctuid pest. Nat. Ecol. Evol. 2017, 1, 1747-1756. [CrossRef]

26. Chen, W.; Yang, X.; Tetreau, G.; Song, X.; Coutu, C.; Hegedus, D.; Blissard, G.; Fei, Z.; Wang, P. A high-quality chromosome-level genome assembly of a generalist herbivore, Trichoplusia ni. Mol. Ecol. Resour. 2019, 19, 485-496. [CrossRef]

27. Zeng, X.D.; Nan, F.; Liang, C.Y.; Song, J.H.; Wang, Q.; Vlak, J.M.; Chen, X.W. Functional analysis of the Autographa californica nucleopolyhedrovirus IAP1 and IAP2. Sci. China Ser. C Life. Sci. 2009, 52, 761-770. [CrossRef]

28. Simão, F.A.; Waterhouse, R.M.; Ioannidis, P.; Kriventseva, E.V.; Zdobnov, E.M. BUSCO: Assessing genome assembly and annotation completeness with single-copy orthologs. Bioinformatics 2015, 31, 3210-3212. [CrossRef] [PubMed]

29. Mita, K.; Kasahara, M.; Sasaki, S.; Nagayasu, Y.; Yamada, T.; Kanamori, H.; Namiki, N.; Kitagawa, M.; Yamashita, H.; Yasukochi, Y.; et al. The genome sequence of silkworm, Bombyx mori. DNA Res. 2004, 11, 27-35. [CrossRef]

30. Kakumani, P.K.; Malhotra, P.; Mukherjee, S.K.; Bhatnagar, R.K. A draft genome assembly of the army worm, Spodoptera frugiperda. Genomics 2014, 104, 134-143. [CrossRef]

31. Legeai, F.; Gimenez, S.; Duvic, B.; Escoubas, J.-M.; Gosselin Grenet, A.-S.; Blanc, F.; Cousserans, F.; Séninet, I.; Bretaudeau, A.; Mutuel, D.; et al. Establishment and analysis of a reference transcriptome for Spodoptera frugiperda. BMC Genom. 2014, 15, 1-14. [CrossRef] [PubMed] 
32. Merzendorfer, H.; Zimoch, L. Chitin metabolism in insects: Structure, function and regulation of chitin synthases and chitinases. J. Exp. Biol. 2003, 206, 4393-4412. [CrossRef]

33. Smith, C.R.; Morandin, C.; Noureddine, M.; Pant, S. Conserved roles of Osiris genes in insect development, polymorphism and protection. J. Evol. Biol. 2018, 31, 516-529. [CrossRef]

34. Nagaraj, R.; Adler, P.N. Dusky-like functions as a Rab11 effector for the deposition of cuticle during Drosophila bristle development. Development 2012, 139, 906-916. [CrossRef] [PubMed]

35. Adler, P.N.; Sobala, L.F.; Thom, D.; Nagaraj, R. dusky-like is required to maintain the integrity and planar cell polarity of hairs during the development of the Drosophila wing. Dev. Biol. 2013, 379, 76-91. [CrossRef] [PubMed]

36. Roch, F.; Alonso, C.R.; Akam, M. Drosophila miniature and dusky encode ZP proteins required for cytoskeletal reorganisation during wing morphogenesis. J. Cell Sci. 2003, 116, 1199-1207. [CrossRef] [PubMed]

37. Tonning, A.; Hemphälä, J.; Tång, E.; Nannmark, U.; Samakovlis, C.; Uv, A. A transient luminal chitinous matrix is required to model epithelial tube diameter in the Drosophila trachea. Dev. Cell 2005, 9, 423-430. [CrossRef] [PubMed]

38. Wang, S.; Jayaram, S.A.; Hemphala“", J.; Senti, K.-A.; Tsarouhas, V.; Jin, H.; Samakovlis, C. Septate-junction-dependent luminal deposition of chitin eeacetylases restricts tube elongation in the Drosophila trachea. Curr. Biol. 2006, 16, 180-185. [CrossRef]

39. Luschnig, S.; Ba, T.; Armbruster, K.; Krasnow, M.A. serpentine and vermiform encode matrix proteins with chitin binding and Deacetylation domains that limit tracheal tube length in Drosophila. Curr. Biol. 2006, 16, 186-194. [CrossRef] [PubMed]

40. Petkau, G.; Wingen, C.; Jussen, L.C.A.; Radtke, T.; Behr, M. Obstructor-A is required for epithelial extracellular matrix dynamics, exoskeleton function, and tubulogenesis. J. Biol. Chem. 2012, 287, 21396-21405. [CrossRef] [PubMed]

41. Wang, G.; Oh, D.; Dassanayake, M. GOMCL: A toolkit to cluster, evaluate, and extract non-redundant associations of Gene Ontology-based functions. BMC Bioinform. 2020, 21, 1-9. [CrossRef]

42. Martin, G.R.; Timpl, R. Laminin and other basement membrane components. Ann. Rev. Cell Biol. 1987, 3, 57-85. [CrossRef]

43. Chi, H.-C.; Hui, C.-F. Primary structure of the Drosophila Laminin B2 chain and comparison with Human, Mouse, and Drosophila Laminin B1 and B2 chains. J. Biol. Chem. 1989, 264, 1543-1550. [CrossRef]

44. Martinek, N.; Shahab, J.; Saathoff, M.; Ringuette, M. Haemocyte-derived SPARC is required for collagen-IV-dependent stability of basal laminae in Drosophila embryos. J. Cell Sci. 2011, 124, 1671-1680. [CrossRef]

45. Shahab, J.; Baratta, C.; Scuric, B.; Godt, D.; Venken, K.J.T.; Ringuette, M.J. Loss of SPARC dysregulates basal lamina assembly to disrupt larval fat body homeostasis in Drosophila melanogaster. Dev. Dyn. 2015, 244, 540-552. [CrossRef]

46. Yamakawa, M.; Tanaka, H. Immune proteins and their gene expression in the silkworm, Bombyx mori. Dev. Comp. Immunol. 1999, 23, 281-289. [CrossRef]

47. Arai, I.; Ohta, M.; Suzuki, A.; Tanaka, S.; Yoshizawa, Y.; Sato, R. Immunohistochemical analysis of the role of hemocytin in nodule formation in the larvae of the silkworm, Bombyx mori. J. Insect Sci. 2013, 13, 1-13. [CrossRef] [PubMed]

48. Ni, W.; Bao, J.; Mo, B.; Liu, L.; Li, T.; Pan, G.; Chen, J.; Zhou, Z. Hemocytin facilitates host immune responses against Nosema bombycis. Dev. Comp. Immunol. 2019, 103, 103495. [CrossRef] [PubMed]

49. Ponnuvel, K.M.; Yamakawa, M. Immune responses against bacterial infection in Bombyx mori and regulation of host gene expression. Curr. Sci. 2002, 83, 447-454.

50. Lesch, C.; Goto, A.; Lindgren, M.; Bidla, G.; Dushay, M.S.; Theopold, U. A role for Hemolectin in coagulation and immunity in Drosophila melanogaster. Dev. Comp. Immunol. 2007, 31, 1255-1263. [CrossRef]

51. Jagdale, S.; Bansode, S.; Joshi, R. Insect Proteases: Structural-Functional Outlook. In Proteases in Physiology and Pathology; Springer Nature: Singapore, 2017; ISBN 9789811025129.

52. Houot, B.; Bousquet, F.; Ferveur, J.F. The consequences of regulation of desat1 expression for pheromone emission and detection in Drosophila melanogaster. Genetics 2010, 185, 1297-1309. [CrossRef] [PubMed]

53. Hayes, J.D.; Flanagan, J.U.; Jowsey, I.R. Glutathione Transferases. Annu Rev. Pharm. Toxicol 2005, 45, 51-88. [CrossRef]

54. Da Fonseca, R.R.; Johnson, W.E.; O'Brien, S.J.; Vasconcelos, V.; Antunes, A. Molecular evolution and the role of oxidative stress in the expansion and functional diversification of cytosolic glutathione transferases. BMC Evol. Biol. 2010, 10, 1-11. [CrossRef]

55. Pan, Q.; Shikano, I.; Felton, G.W.; Liu, T.-X.; Hoover, K. Host permissiveness to baculovirus influences time-dependent immune responses and fitness costs. Insect Sci. 2021, 28, 103-114. [CrossRef]

56. Katsuma, S.; Kawaoka, S.; Mita, K.; Shimada, T. Genome-wide survey for baculoviral host homologs using the Bombyx genome sequence. Insect Biochem. Mol. Biol. 2008, 38, 1080-1086. [CrossRef] [PubMed]

57. Gilbert, C.; Chateigner, A.; Ernenwein, L.; Barbe, V.; Annie, B.; Herniou2, E.A.; Cordaux, R. Population genomics supports baculoviruses as vectors of horizontal transfer of insect transposons. Nat. Commun. 2014, 5, 1-9. [CrossRef] [PubMed]

58. Stewart, T.M.; Huijskens, I.; Willis, L.G.; Theilmann, D.A. The Autographa californica Multiple Nucleopolyhedrovirus ie0 - ie1 gene complex is essential for wild-type virus replication, but either IE0 or IE1 can support virus growth. J. Virol. 2005, 79, 4619-4629. [CrossRef] [PubMed]

59. Gómez-Sebastián, S.; López-Vidal, J.; Escribano, J.M. Significant productivity improvement of the baculovirus expression vector system by engineering a novel expression cassette. PLoS ONE 2014, 9. [CrossRef] [PubMed]

60. Chisholm, G.E.; Henner, D.J. Multiple early transcripts and splicing of the Autographa californica nuclear polyhedrosis virus IE-1 gene. J. Virol. 1988, 62, 3193-3200. [CrossRef] [PubMed]

61. Kovacs, G.R.; Guarino, L.A.; Summers, M.D. Novel regulatory properties of the IE1 and IE0 transactivators encoded by the baculovirus Autographa californica multicapsid nuclear polyhedrosis virus. J. Virol. 1991, 65, 5281-5288. [CrossRef] 
62. Choi, J.Y.; Roh, J.Y.; Wang, Y.; Zhen, Z.; Tao, X.Y.; Lee, J.H.; Liu, Q.; Kim, J.S.; Shin, S.W.; Je, Y.H. Analysis of genes expression of Spodoptera exigua Larvae upon AcMNPV infection. PLoS ONE 2012, 7, e42462. [CrossRef]

63. Guarino, L.A.; Dong, W.E.N.; Xu, B.I.N.; Broussard, D.R.; Davis, R.W.; Jarvis, D.L. Baculovirus phosphoprotein pp31 is associated with virogenic stroma. J. Virol. 1992, 66, 7113-7120. [CrossRef]

64. Guo, Z.J.; Qiu, L.H.; An, S.H.; Yao, Q.; Park, E.Y.; Chen, K.P.; Zhang, C.X. Open reading frame 60 of the Bombyx mori nucleopolyhedrovirus plays a role in budded virus production. Virus Res. 2010, 151, 185-191. [CrossRef]

65. Ishimwe, E.; Hodgson, J.J.; Clem, R.J.; Passarelli, A.L. Reaching the melting point: Degradative enzymes and protease inhibitors involved in baculovirus infection and dissemination. Virology 2015, 479-480, 637-649. [CrossRef]

66. Braunagel, S.C.; He, H.; Ramamurthy, P.; Summers, M.D. Transcription, translation, and cellular localization of three Autographa californica nuclear polyhedrosis virus structural proteins: ODV-E18, ODV-E35, and ODV-EC27. Virology 1996, 114, 100-114. [CrossRef]

67. Heaton, N.S.; Randall, G. Multifaceted roles for lipids in viral infection. Trends Microbiol. 2011, 19, 368-375. [CrossRef] [PubMed]

68. Ohkawa, T.; Welch, M.D. Baculovirus Actin-based motility drives nuclear envelope disruption and nuclear egress report. Curr. Biol. 2018, 28, 1-7. [CrossRef] [PubMed]

69. Mu, J.; Zhang, Y.; Hu, Y.; Hu, X.; Zhou, Y.; Zhao, H.; Pei, R.; Wu, C.; Chen, J.; Zhao, H.; et al. Autographa californica multiple nucleopolyhedrovirus Ac34 protein retains cellular Actin-Related protein 2/3 complex in the nucleus by subversion of CRM1dependent nuclear export. PLoS Pathog. 2016, 12, 1-22. [CrossRef]

70. Qiu, J.; Tang, Z.; Yuan, M.; Wu, W.; Yang, K. The 91-205 amino acid region of AcMNPV ORF34 (Ac34), which comprises a potential $\mathrm{C} 3 \mathrm{H}$ zinc finger, is required for its nuclear localization and optimal virus multiplication. Virus Res. 2017, 228, 79-89. [CrossRef]

71. Cai, Y.; Long, Z.; Qiu, J.; Yuan, M.; Li, G.; Yang, K. An ac34 deletion mutant of Autographa californica Nucleopolyhedrovirus exhibits delayed late gene expression and a lack of virulence in vivo. J. Virol. 2012, 86, 10432-10443. [CrossRef] [PubMed]

72. Kelly, K.K.; Meadows, S.M.; Cripps, R.M. Drosophila MEF2 is a direct regulator of Actin57B transcription in cardiac, skeletal, and visceral muscle lineages. Mech Dev. 2002, 110, 39-50. [CrossRef]

73. Clem, R.J.; Miller, L.K. Control of programmed cell death by the baculovirus genes p35 and iap. Mol. Cell Biol. 1994, 14, 5212-5222. [CrossRef]

74. Lu, A.; Miller, L.K. Species-specific effects of the hcf-1 gene on baculovirus virulence. J. Virol. 1996, 70, 5123-5130. [CrossRef]

75. Tachibana, A.; Hamajima, R.; Tomizaki, M.; Kondo, T.; Nanba, Y.; Yamada, H.; Ikeda, M. HCF-1 encoded by baculovirus AcMNPV is required for productive nucleopolyhedrovirus infection of. Sci. Rep. 2017, 7, 1-10. [CrossRef]

76. Clem, R.J.; Miller, L.K. Apoptosis reduces both the in vitro replication and the in vivo infectivity of a baculovirus. J. Virol. 1993, 67, 3730-3738. [CrossRef] [PubMed]

77. Ikeda, M.; Yamada, H.; Ito, H.; Kobayashi, M. Baculovirus IAP1 induces caspase-dependent apoptosis in insect cells. J. Gen. Virol 2011, 92, 2654-2663. [CrossRef] [PubMed]

78. McLachlin, J.R.; Escobar, J.C.; Harrelson, J.A.; Clem, R.J.; Miller, L.K. Deletions in the Ac-iap1 gene of the baculovirus AcMNPV occur spontaneously during serial passage and confer a cell line-specific replication advantage. Virus Res. 2001, 81, 77-91. [CrossRef]

79. Reilly, D.R.O; Miller, L.K. A Baculovirus blocks insect molting by producing Ecdysteroid UDP-Glucosyl Transferase. Science 1989, 245, 1110-1112. [CrossRef]

80. Rao, R.; Fiandra, L.; Giordana, B.; De Eguileor, M.; Congiu, T.; Burlini, N.; Arciello, S.; Corrado, G.; Pennacchio, F. AcMNPV ChiA protein disrupts the peritrophic membrane and alters midgut physiology of Bombyx mori larvae. Insect Biochem. Mol. Biol. 2004, 34, 1205-1213. [CrossRef]

81. Erlandson, M.A.; Toprak, U.; Hegedus, D.D. Role of the peritrophic matrix in insect-pathogen interactions. J. Insect Physiol. 2019, 117, 103894. [CrossRef]

82. He, L.; Li, N.; Chen, Y.; Liu, S. Regulation of Chitinase in Spodoptera exigua (Hübner) (Lepidoptera:Noctuidae) during infection by Heliothis virescens. Front. Physiol. 2020, 11, 1-11. [CrossRef]

83. Romoser, W.S.; Turell, M.J.; Lerdthusnee, K.; Neira, M.; Dohm, D.; Ludwig, G.; Wasieloski, L. Pathogenesis of Rift Valley fever virus in mosquitoes-Tracheal conduits \& the basal lamina as an extra-cellular barrier. In Infectious Diseases from Nature: Mechanisms of Viral Emergence and Persistence; Peters, C.J., Calisher, C.H., Eds.; Springer: Vienna, Austria, 2005; pp. 89-100.

84. Passarelli, A.L. Barriers to success: How baculoviruses establish efficient systemic infections. Virology 2012, 411, 383-392. [CrossRef]

85. Engelhard, E.K.; Kam-Morgan, L.N.; Washburn, J.O.; Volkman, L.E. The insect tracheal system: A conduit for the systemic spread of Autographa californica M nuclear polyhedrosis virus. Proc. Natl. Acad. Sci. USA 1994, 91, 3224-3227. [CrossRef]

86. Hawtin, R.E.; Arnold, K.; Ayres, M.D.; Zanotto, P.M.d.A.; Howard, S.C.; Gooday, G.W.; Chappell, L.H.; Kitts, P.A.; King, L.A.; Possee, R.D. Identification and preliminary characterization of a Chitinase gene in the Autographa californica nuclear polyhedrosisvirus genome. Virology 1995, 212, 673-685. [CrossRef]

87. Daimon, T.; Katsuma, S.; Kang, W.K.; Shimada, T. Comparative studies of Bombyx mori nucleopolyhedrovirus chitinase and its host ortholog, BmChi-h. Biochem. Biophys. Res. Commun. 2006, 345, 825-833. [CrossRef]

88. Hawtin, R.E.; Zarkowska, T.; Arnold, K.; Thomas, C.J.; Gooday, G.W.; King, L.A.; Kuzio, J.A.; Possee, R.D. Liquefaction of Autographa californica nucleopolyhedrovirus-infected insects is dependent on the integrity of virus-encoded chitinase and cathepsin genes. Virology 1997, 238, 243-253. [CrossRef] 
89. Campbell, A.G.; Fessler, L.I.; Salo, T.; Fesslerq, J.H. Papilin: A Drosophila proteoglycan-like sulfated glycoprotein from basement membranes. J. Biol. Chem. 1987, 262, 17605-17612. [CrossRef]

90. Hortsch, M.; Marikar, Y.; Fishman, S.; Soneral, S.N.; Dong, R.; Jacobs, J.R. The expression of MDP-1, a component of Drosophila embryonic basement membranes, is modulated by apoptotic cell death. Int, J. Dev. Biol. 1998, 42, 33-42.

91. Kramerova, I.A.; Kawaguchi, N.; Fessler, L.I.; Nelson, R.E.; Chen, Y.; Kramerov, A.A.; Kusche-gullberg, M.; Kramer, J.M.; Ackley, B.D.; Sieron, A.L.; et al. Papilin in development; a pericellular protein with a homology to the ADAMTS metalloproteinases. Development 2000, 127, 5475-5485.

92. Beck, K.; Hunter, I.; Engel, J. Structure and function of laminin: Anatomy of a multidomain glycoprotein. FASEB J. 1990, 4, 148-160. [CrossRef] [PubMed]

93. Keeley, D.P.; Hastie, E.; Jayadev, R.; Kelley, L.C.; Chi, Q.; Payne, S.G.; Jeger, J.L.; Hoffman, B.D.; Sherwood, D.R. Comprehensive endogenous tagging of basement membrane components reveals dynamic movement within the matrix scaffolding. Dev. Cell 2020, 54, 60-74.e7. [CrossRef]

94. Means, J.C.; Passarelli, A.L. Viral fibroblast growth factor, matrix metalloproteases, and caspases are associated with enhancing systemic infection by baculoviruses. Proc. Natl. Acad. Sci. USA 2010, 107, 9825-9830. [CrossRef]

95. Monsma, S.A.; Oomens, A.G.P.; Blissard, G.W. The GP64 envelope fusion protein is an essential baculovirus protein required for cell-to-cell transmission of infection. J. Virol. 1996, 70, 4607-4616. [CrossRef] [PubMed]

96. Li, J.; Sun, Y.; Li, Y.; Liu, X.; Yue, Q.; Li, Z. Inhibition of cellular fatty acid synthase impairs replication of budded virions of Autographa californica multiple nucleopolyhedrovirus in Spodoptera frugiperda cells. Virus Res. 2018, 252, 41-47. [CrossRef] [PubMed]

97. Munger, J.; Bennett, B.D.; Parikh, A.; Feng, X.; Rabitz, H.A.; Shenk, T.; Rabinowitz, J.D. Systems-level metabolic flux profiling identifies fatty acid synthesis as a target for antiviral therapy. Nat. Biotechnol. 2010, 26, 1179-1186. [CrossRef]

98. Breitenbach, J.E.; Shelby, K.S.; Popham, H.J.R. Baculovirus induced transcripts in hemocytes from the larvae of Heliothis virescens. Viruses 2011, 3, 2047-2064. [CrossRef] [PubMed]

99. Bousquet, F.; Ferveur, J.F. desat1 A Swiss army knife for pheromonal communication and reproduction? Fly (Austin) 2012, 6, 102-107. [CrossRef]

100. Köhler, K.; Brunner, E.; Xue, L.G.; Boucke, K.; Greber, U.F.; Mohanty, S.; Barth, J.M.I.; Wenk, M.R.; Hafen, E. A combined proteomic and genetic analysis identifies a role for the lipid desaturase Desat1 in starvation-induced autophagy in Drosophila. Autophagy 2009, 5, 980-990. [CrossRef] [PubMed]

101. He, C.; Klionsky, D.J. Regulation mechanisms and signaling pathways of autophagy. Annu Rev. Genet. 2009, 43, 67-93. [CrossRef]

102. Roxstrom-Lindquist, K.; Terenius, O.; Faye, I. Parasite-specific immune response in adult Drosophila melanogaster: A genomic study. EMBO Rep. 2004, 5, 207-212. [CrossRef]

103. Qiu, Y.; Tittiger, C.; Wicker-Thomas, C.; Le Goff, G.; Young, S.; Wajnberg, E.; Fricaux, T.; Taquet, N.; Blomquist, G.J.; Feyereisen, R. An insect-specific P450 oxidative decarbonylase for cuticular hydrocarbon biosynthesis. Proc. Natl. Acad. Sci. USA 2012, 109, 14858-14863. [CrossRef]

104. Cerenius, L.; Kawabata, S.I.; Lee, B.L.; Nonaka, M.; Söderhäll, K. Proteolytic cascades and their involvement in invertebrate immunity. Trends Biochem. Sci. 2010, 35, 575-583. [CrossRef]

105. Lavine, M.D.; Strand, M.R. Insect hemocytes and their role in immunity. Insect Immunol. 2008, 32, 25-47. [CrossRef]

106. Zhao, P.; Wang, G.H.; Dong, Z.M.; Duan, J.; Xu, P.Z.; Cheng, T.C.; Xiang, Z.H.; Xia, Q.Y. Genome-wide identification and expression analysis of serine proteases and homologs in the silkworm Bombyx mori. BMC Genom. 2010, 11, 1-11. [CrossRef] [PubMed]

107. Washburn, J.O.; Haas-Stapleton, E.J.; Tan, F.F.; Beckage, N.E.; Volkman, L.E. Co-infection of Manduca sexta larvae with polydnavirus from Cotesia congregata increases susceptibility to fatal infection by Autographa californica M Nucleopolyhedrovirus. J. Insect Physiol. 2000, 46, 179-190. [CrossRef]

108. Lavington, E.; Cogni, R.; Kuczynski, C.; Koury, S.; Behrman, E.L.; O’brien, K.R.; Schmidt, P.S.; Eanes, W.F. A small systemhigh-resolution study of metabolic adaptation in the central metabolic pathway to temperate climates in Drosophila melanogaster. Mol. Biol. Evol. 2014, 31, 2032-2041. [CrossRef]

109. Wise, E.M.; Ball, E.G. Malic enzyme and lipogenesis. Proc. Natl. Acad. Sci. USA 1964, 52, 1255-1263. [CrossRef]

110. Merritt, T.J.S.; Duvernell, D.; Eanes, W.F. Natural and synthetic alleles provide complementary insights into the nature of selection acting on the Men polymorphism of Drosophila melanogaster. Genetics 2005, 171, 1707-1718. [CrossRef]

111. Geer, B.W.; Krochko, D.; Williamson, J.H. Ontogeny, cell distribution, and the physiological role of NADP-malic enzyme in Drosophila melanogaster. Biochem. Genet. 1979, 17, 867-879. [CrossRef] [PubMed]

112. Lee, M.; Yoon, C.S.; Yi, J.; Cho, J.R.; Kim, H.S. Cellular immune responses and FAD-glucose dehydrogenase activity of Mamestra brassicae (Lepidoptera: Noctuidae) challenged with three species of entomopathogenic fungi. Physiol. Entomol. 2005, 30, $287-292$. [CrossRef]

113. Trienens, M.; Rohlfs, M. A potential collective defense of Drosophila larvae against the invasion of a harmful fungus. Front. Ecol. Evol. 2020, 8, 1-10. [CrossRef]

114. Gomez-Diaz, C.; Bargeton, B.; Abuin, L.; Bukar, N.; Reina, J.H.; Bartoi, T.; Graf, M.; Ong, H.; Ulbrich, M.H.; Masson, J.F.; et al. A CD36 ectodomain mediates insect pheromone detection via a putative tunnelling mechanism. Nat. Commun. 2016, 7, 1-17. [CrossRef] [PubMed] 
115. Benton, R.; Vannice, K.S.; Vosshall, L.B. An essential role for a CD36-related receptor in pheromone detection in Drosophila. Nature 2007, 450, 289-293. [CrossRef] [PubMed]

116. Mast, J.D.; De Moraes, C.M.; Alborn, H.T.; Lavis, L.D.; Stern, D.L. Evolved differences in larval social behavior mediated by novel pheromones. Elife 2014, 3, e04205. [CrossRef]

117. Sabatier, L.; Jouanguy, E.; Dostert, C.; Zachary, D.; Dimarcq, J.L.; Bulet, P.; Imler, J.L. Pherokine-2 and -3: Two Drosophila molecules related to pheromone/odor-binding proteins induced by viral and bacterial infections. Eur. J. Biochem. 2003, 270, 3398-3407. [CrossRef]

118. Labeur, C.; Dallerac, R.; Wicker-Thomas, C. Involvement of desat1 gene in the control of Drosophila melanogaster pheromone biosynthesis. Genetica 2002, 114, 269-274. [CrossRef] [PubMed]

119. Bousquet, F.; Nojima, T.; Houot, B.; Chauvel, I.; Chaudy, S.; Dupas, S.; Yamamoto, D.; Ferveur, J.-F. Expression of a desaturase gene, desat1, in neural and nonneural tissues separately affects perception and emission of sex pheromones in Drosophila. Proc. Natl. Acad. Sci. USA 2012, 109, 249-254. [CrossRef] [PubMed]

120. Sim, S.; Ramirez, L.; Dimopoulos, G. Dengue virus infection of the Aedes aegypti salivary gland and chemosensory apparatus induces genes that modulate infection and blood-feeding behavior. PLoS Pathog. 2012, 8, e1002631. [CrossRef] [PubMed]

121. Bartholomay, L.C.; Cho, W.L.; Rocheleau, T.A.; Boyle, J.P.; Beck, E.T.; Fuchs, J.F.; Liss, P.; Rusch, M.; Butler, K.M.; Wu, R.C.C.; et al. Description of the transcriptomes of immune response-activated hemocytes from the mosquito vectors Aedes aegypti and Armigeres subalbatus. Infect. Immun 2004, 72, 4114-4126. [CrossRef]

122. Schieber, M.; Chandel, N.S. ROS function in redox signaling. Curr. Biol. 2014, 24, 453-462. [CrossRef]

123. Rohrmann, G.F. Chapter 12, The AcMNPV Genome: Gene Content, Conservation, and Function. In Baculovirus Molecular Biology, 3rd ed.; National Center for Biotechnology Information: Bethesda, MD, USA, 2013; pp. 1-84.

124. O'Reilly, D.R.; Miller, L.K. Regulation of expression of a baculovirus ecdysteroid UDPglucosyltransferase gene. J. Virol. 1990, 64, 1321-1328. [CrossRef]

125. Hoover, K.; Grove, M.; Gardner, M.; Hughes, D.P.; Mcneil, J.; Slavicek, J. A Gene for an extended phenotype. Science 2011, 333, 1401. [CrossRef]

126. Ros, V.I.D.; Van Houte, S.; Hemerik, L.; Van Oers, M.M. Baculovirus-induced tree-top disease: How extended is the role of egt as a gene for the extended phenotype? Mol. Ecol. 2015, 24, 249-258. [CrossRef]

127. Van Houte, S.; Ros, V.I.D.; Van Oers, M.M. Hyperactivity and tree-top disease induced by the baculovirus AcMNPV in Spodoptera exigua larvae are governed by independent mechanisms. Naturwissenschaften 2014, 101, 347-350. [CrossRef]

128. Herrero, S.; Ansems, M.; Van Oers, M.M.; Vlak, J.M.; Bakker, P.L.; de Maagd, R.A. REPAT, a new family of proteins induced by bacterial toxins and baculovirus infection in Spodoptera exigua. Insect Biochem. Mol. Biol. 2007, 37, 1109-1118. [CrossRef]

129. Merzendorfer, H. Chitin synthesis inhibitors: Old molecules and new developments. Insect Sci. 2013, 20, 121-138. [CrossRef] [PubMed]

130. Zhu, K.Y.; Merzendorfer, H.; Zhang, W.; Zhang, J.; Muthukrishnan, S. Biosynthesis, turnover, and functions of chitin in insects. Annu. Rev. Entomol. 2016, 61, 177-196. [CrossRef] [PubMed]

131. Douris, V.; Steinbach, D.; Panteleri, R.; Livadaras, I.; Pickett, J.A.; Van Leeuwen, T.; Nauen, R.; Vontas, J. Resistance mutation conserved between insects and mites unravels the benzoylurea insecticide mode of action on chitin biosynthesis. Proc. Natl. Acad. Sci. USA 2016, 113, 14692-14697. [CrossRef] [PubMed]

132. Moussian, B.; Schwarz, H.; Bartoszewski, S.; Nu, C. Involvement of chitin in exoskeleton morphogenesis in Drosophila melanogaster. J. Morphol. 2005, 264, 117-130. [CrossRef]

133. Cook, D.R.; Leonard, B.R.; Gore, J. Field and laboratory performance of novel insecticides against armyworms (Lepidoptera: Noctuidae). Fla. Entomol. 2006, 87, 433-439. [CrossRef]

134. IRAC South Africa. Integrated Pest Management (IPM) E Insect Resistance Management (IRM) for Fall Armyworm in South African Maize; IRAC: Pretoria, South Africa, 2018; pp. 1-21.

135. Powell, G.F.; Ward, D.A.; Prescott, M.C.; Spiller, D.G.; White, M.R.H.; Turner, P.C.; Earley, F.G.P.; Phillips, J.; Rees, H.H. The molecular action of the novel insecticide, Pyridalyl. Insect Biochem. Mol. Biol. 2011, 41, 459-469. [CrossRef]

136. San Miguel, K.; Scott, J.G. The next generation of insecticides: DsRNA is stable as a foliar-applied insecticide. Pest Manag. Sci. 2016, 72, 801-809. [CrossRef]

137. Liu, Z.; Wang, X.; Dai, Y.; Wei, X.; Ni, M.; Zhang, L.; Zhu, Z. Expressing double-stranded RNAs of insect hormone-related genes enhances baculovirus insecticidal activity. Int. J. Mol. Sci. 2019, 20, 419. [CrossRef]

138. Bonning, B.C.; Hirst, M.; Possee, R.D.; Hammock, B.D. Further development of a recombinant baculovirus insecticide expressing the enzyme juvenile hormone esterase from Heliothis virescens. Insect Biochem. Mol. Biol. 1992, 22, 453-458. [CrossRef]

139. Chen, E.; Kolosov, D.; O’Donnell, M.J.; Erlandson, M.A.; McNeil, J.N.; Donly, C. The effect of diet on midgut and resulting changes in infectiousness of AcMNPV baculovirus in the cabbage looper, Trichoplusia ni. Front. Physiol. 2018, 9, 1-11. [CrossRef]

140. Wilson, K.; Grzywacz, D.; Curcic, I.; Scoates, F.; Harper, K.; Rice, A.; Paul, N.; Dillon, A. A novel formulation technology for baculoviruses protects biopesticide from degradation by ultraviolet radiation. Sci. Rep. 2020, 10, 13301. [CrossRef]

141. Cory, J.S.; Hirst, M.L.; Williams, T.; Hails, R.S.; Goulson, D.; Green, B.M.; Carty, T.M.; Possee, R.D.; Cayley, P.J.; Bishop, D.H.L. Field trial of a genetically improved baculovirus insecticide. Nature 1994, 370, 138-140. [CrossRef] 
142. Shim, H.J.; Choi, J.Y.; Wang, Y.; Tao, X.Y.; Liu, Q.; Roh, J.Y.; Kim, J.S.; Kim, W.J.; Woo, S.D.; Jin, B.R.; et al. Neurobactrus, a novel, highly effective, and environmentally friendly recombinant baculovirus insecticide. Appl. Environ. Microbiol. 2013, 79, 141-149. [CrossRef]

143. Das, S.; Goswami, A.; Debnath, N. Application of Baculoviruses as Biopesticides and the Possibilities of Nanoparticle Mediated Delivery in Nano-Biopesticides Today and Future Perspectives; Elsevier Inc.: Oxford, UK, 2019; ISBN 9780128158296.

144. Collett, D. Modelling Binary Data; Chapman \& Hall/CRC: Boca Raton, FL, USA, 2003.

145. R Core Team. A Language and Environment for Statistical Computing; R Development Core Team: Wien, Austria, 2018.

146. Plummer, M. JAGS: A program for analysis of bayesian graphical models using gibbs sampling. Proc. Dsc. 2003, 1-10.

147. Su, Y.; Yajima, M. Package 'R2jags'; CRAN: Vienna, Austria, 2015.

148. Link, W.A.; Eaton, M.J. On thinning of chains in MCMC. Methods Ecol. Evol. 2012, 3, 112-115. [CrossRef]

149. Gelman, A.; Carlin, J.B.; Stern, H.S.; Rubin, D.B. Bayesian Data Analysis; Taylor \& Francis: Oxford, UK, 2014.

150. Gelman, A.; Meng, X.L.; Stern, H. Posterior predictive assessment of model fitness via realized discrepancies. Stat. Sin. 1996, $6,733-760$.

151. Kéry, M. Introduction to WinBUGS for Ecologists; Elsevier: Amsterdam, The Netherlands, 2010.

152. Granados, R.R.; Lawler, K.A. In vivo pathway of Autographa californica baculovirus invasion and infection. Virology 1981, 308, 297-308. [CrossRef]

153. Fan, L.; Wang, G.; Hu, W.; Pantha, P.; Tran, K.-N.; Zhang, H.; An, L.; Dassanayake, M.; Qiu, Q.-S. Transcriptomic view of survival during early seedling growth of the extremophyte Haloxylon ammodendron. Plant. Physiol. Biochem. 2018, 132, 475-489. [CrossRef]

154. Grabherr, M.G.; Haas, B.J.; Yassour, M.; Levin, J.Z.; Thompson, D.A.; Amit, I.; Adiconis, X.; Fan, L.; Raychowdhury, R.; Zeng, Q.; et al. Full-length transcriptome assembly from RNA-Seq data without a reference genome. Nat. Biotechnol. 2011, 29, 644-652. [CrossRef]

155. Oh, D.; Barkla, B.J.; Vera-estrella, R.; Pantoja, O.; Lee, S.; Bohnert, H.J.; Dassanayake, M. Cell type-specific responses to salinity-the epidermal bladder cell transcriptome of Mesembryanthemum crystallinum. New Phytol. 2015, 207, 627-644. [CrossRef] [PubMed]

156. Li, W.; Godzik, A. Cd-hit: A fast program for clustering and comparing large sets of protein or nucleotide sequences. Bioinformatics 2006, 22, 1658-1659. [CrossRef] [PubMed]

157. Langmead, B.; Trapnell, C.; Pop, M.; Salzberg, S.L. Ultrafast and memory-efficient alignment of short DNA sequences to the human genome. Genome Biol. 2009, 10, R25. [CrossRef] [PubMed]

158. Tarazona, S.; Furió-Tarí, P.; Turrà, D.; Di Pietro, A.; Nueda, M.J.; Ferrer, A.; Conesa, A. Data quality aware analysis of differential expression in RNA-seq with NOISeq R/Bioc package. Nucleic Acids Res. 2015, 43, e140. [CrossRef] [PubMed]

159. Maere, S.; Heymans, K.; Kuiper, M. BiNGO: A Cytoscape plugin to assess overrepresentation of Gene Ontology categories in Biological Networks. Bioinformatics 2005, 21, 3448-3449. [CrossRef]

160. Shrestha, A.; Bao, K.; Chen, Y.-R.; Chen, W.; Wang, P.; Fei, Z.; Blissard, G.W. Global analysis of Baculovirus Autographa californica Multiple Nucleopolyhedrovirus gene expression in the midgut of the lepidopteran host Trichoplusia ni. J. Virol. 2018, 92, e01277-18. [CrossRef] 